Check for updates

Cite this: RSC Adv., 2018, 8, 2521

Received 10th November 2017 Accepted 2nd January 2018

DOI: $10.1039 / c 7 r a 12299 c$

rsc.li/rsc-advances

\section{Magnetite-based adsorbents for sequestration of radionuclides: a review}

\begin{abstract}
Syed M. Husnain, abc Wooyong Um, (D) ab Woojin-Lee ${ }^{d}$ and Yoon-Seok Chang (DD *a
As a result of extensive research efforts by several research groups, magnetite-based materials have gained enormous attention in diverse fields including biomedicine, catalysis, energy and data storage devices, magnetic resonance imaging, and environmental remediation. Owing to their low production cost, ease of modification, biocompatibility, and superparamagnetism, the use of these materials for the abatement of environmental toxicants has been increasing continuously. Here we focus on the recent advances in the use of magnetite-based adsorbents for removal of radionuclides (such as ${ }^{137} \mathrm{Cs}(\mathrm{I}),{ }^{155} \mathrm{Eu}\left({ }^{\prime \prime I}\right),{ }^{90} \mathrm{Sr}(\mathrm{II})$, ${ }^{238} \mathrm{U}(\mathrm{VI})$, etc.) from diverse aqueous phases. This review summarizes the preparation and surface modification of magnetite-based adsorbents, their physicochemical properties, adsorption behavior and mechanism, and diverse conventional and recent environmental technological options for the treatment of water contaminated with radionuclides. In addition, case studies for the removal of radionuclides from actual contaminated sites are discussed, and finally the optimization of magnetite-based remedial solutions is presented for practical application.
\end{abstract}

\section{Introduction}

Over the last few decades, there has been an increasing global concern over public health issues due to environmental pollution caused by radionuclides, ${ }^{\mathbf{1 , 2}}$ heavy metals, ${ }^{3}$ and pesticides. ${ }^{\mathbf{4}}$ Radionuclides are chemical elements emitting either $\alpha-, \beta-$, or $\gamma$-rays, or neutrons. They can be classified on the basis of their origin such as naturally occurring and anthropogenic (Fig. 1). Among the naturally occurring radionuclides, there are further three types including primordial $\left({ }^{238} \mathrm{U},{ }^{235} \mathrm{U},{ }^{232} \mathrm{Th},{ }^{4} \mathrm{~K}\right)$, secondary $\left({ }^{210} \mathrm{~Pb},{ }^{26} \mathrm{Al},{ }^{36} \mathrm{Cl},{ }^{54} \mathrm{Mn}\right.$ etc. $)$, and cosmogenic radionuclides $\left({ }^{3} \mathrm{H},{ }^{14} \mathrm{C},{ }^{7} \mathrm{Be}\right.$ etc. $)$. Anthropogenic radionuclides include isotopes of ${ }^{239} \mathrm{Pu},{ }^{129} \mathrm{I},{ }^{137} \mathrm{Cs},{ }^{99} \mathrm{Tc}$, and ${ }^{241} \mathrm{Am}$ present in radioactive waste. ${ }^{5}$ Radioactive waste generated by nuclear facilities operation and weapon production can be categorized on the basis of radioactivity level such as low, intermediate, and high level waste. The major contaminant sources from which the radionuclides originate are nuclear power plants, nuclear weapon production and testing sites, commercial nuclear fuel processing units, and release from failed geological repositories. $^{2}$

Radionuclides can reside in ambient air, soil, and water after their emission from sources, which is why a few radionuclides

\footnotetext{
${ }^{a}$ School of Environmental Science and Engineering, Pohang University of Science and Technology (POSTECH), Pohang 790-784, Republic of Korea

${ }^{b}$ Division of Advanced Nuclear Engineering, POSTECH, Republic of Korea

${ }^{c}$ Chemistry Division, Directorate of Science, Pakistan Institute of Nuclear Science and Technology (PINSTECH), P.O. Nilore, Islamabad, 45650 Pakistan

${ }^{d}$ Department of Civil Engineering, Nazarbayev University, Astana 010000, Republic of Kazakhstan
}

have been detected in soil, sediment, air, and aquatic environments. Past atmospheric weapons testing and some emissions from active nuclear power plants and irradiated fuel reprocessing activities can transfer radionuclides to the ground via rain water. ${ }^{6}$ They could be involved in complex reactions with soil organic matter. ${ }^{7}$ Their presence in upper layer of soil and sediment are two main sources for their introduction to the food chain. ${ }^{8}$ Some of anthropogenic and naturally occurring radionuclides such as ${ }^{222} \mathrm{Rn},{ }^{226} \mathrm{Ra},{ }^{228} \mathrm{Ra},{ }^{238} \mathrm{U},{ }^{234} \mathrm{U}$, and ${ }^{232} \mathrm{Th}$ are commonly found in groundwater around the world. ${ }^{9}$ Exposure to the water contaminated with radionuclides may have more detrimental health concerns because of chemical as well as radiological toxicities. These radionuclides cause diseases

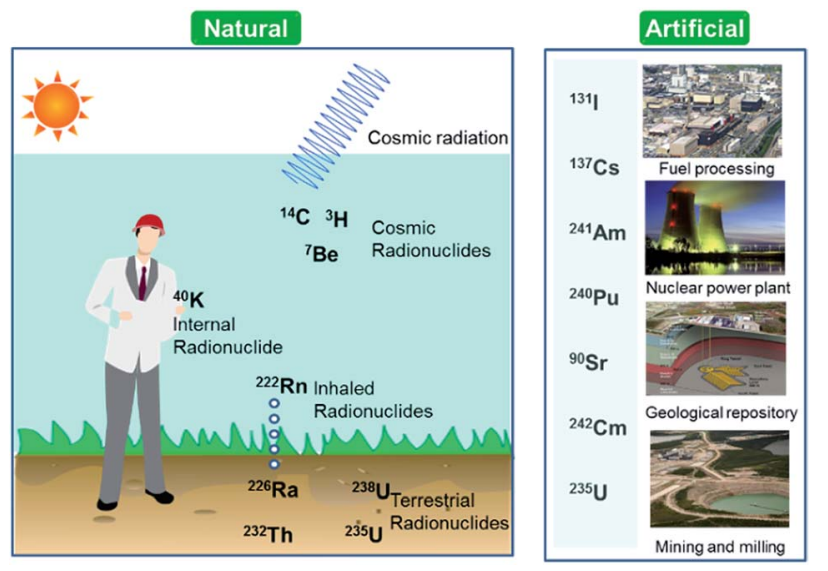

Fig. 1 Classification of radionuclides in the environment. 
such as neurological disorders, birth defects, infertility, and various types of cancers in different organs like lungs, thyroid, colon esophagus, breast, and ovary. ${ }^{\mathbf{1 0 - 1 2}}$ Owing to the dual toxic nature, the U.S. Environmental Protection Agency (EPA) recommended maximum contaminant levels (MCLs) for radionuclides in water; specifically, $15 \mathrm{pCi}^{-1}(0.55 \mathrm{~Bq})$ for alpha emitters, 4 mrem per year ( $40 \mu \mathrm{Sv}$ per year) for beta and photon emitters, 5 pCi L ${ }^{-1}\left(0.18 \mathrm{~Bq} \mathrm{~L}^{-1}\right)$ for radium $\left({ }^{226} \mathrm{Ra} /{ }^{228} \mathrm{Ra}\right)$, and $30 \mu \mathrm{g} \mathrm{L}^{-1}\left(0.74 \mathrm{~Bq} \mathrm{~L}^{-1}\right)$ for uranium have been established as drinking water standards. ${ }^{13}$

Monitoring and subsequent removal of these radionuclides from the contaminated water is one of the major environmental remediation interests today. Effluents discharged during the operation of nuclear facilities are regularly monitored to ensure the radioactivity level sufficiently lower than permissible limit. To treat the toxic radioactive contaminants, many conventional techniques including precipitation, reverse osmosis (RO), ion exchange (IE), electrodialysis, solvent extraction, and evaporation were developed and applied. ${ }^{\mathbf{1 4 - 1 6}}$ Among these; precipitation, IE, and RO are widely used for ex situ treatment of groundwater contaminated with radionuclides. Precipitation is relatively simple, reliable, and cost effective to convert the majority of the soluble radionuclides into insoluble hydroxides, sulfides, or carbonates minerals. RO separates dissolved solids by passing the contaminated water through semipermeable membrane. Although the conventional technologies have made significant contributions to the environmental protection of human society in the last century, the continuous and everincreasing demands for pure water is gradually pushing the conventional technologies to their limits and likely unable to meet strict regulations of the U.S EPA and the World Health Organization (WHO) standards.

Recently, nano-materials such as graphene oxide (GO), nanoscale zero valent iron (nZVI), self-assembled mono layers on mesoporous supports (SAMMS), carbon nanotubes (CNTs), zeolites, and nano-sized filtration membranes have been examined for the removal of radionuclides. ${ }^{17}$ All of these remedial alternatives have their pros and cons, for example, CNTs and GO have excellent ability to encapsulate various radionuclides with high adsorption capability but the methods to prepare them in bulk amount are difficult as well as expensive. Similarly, zeolites are the ecologically benign materials for removal of radionuclides but they suffer from poor stability due to $\mathrm{Si}$ and $\mathrm{Al}$ dissolution at alkaline $\mathrm{pH}$ range. ${ }^{18}$ Among the aforementioned established technologies, adsorption using magnetic nanoparticles (MNPs) under certain conditions has a definite edge (Fig. 2) over other methods due to its simplicity, effectiveness at removing dissolved contaminants in low concentration range $\left(\mu \mathrm{g} \mathrm{L}^{-1}\right.$ to $\left.\mathrm{mg} \mathrm{L}^{-1}\right)$, high recovery, environment-benignity, and low maintenance cost. ${ }^{19}$ The main advantage of magnetic adsorbent and its facile separation is to reduce the radiation exposure to radiological worker in high radiation field so that the entire remediation process can be systematically regulated and controlled remotely. To treat the radioactive contaminants from aqueous waste streams, the MNPs need to be properly dispersed in a reactor or in situ. The extraction of radionuclides on MNPs can be achieved in

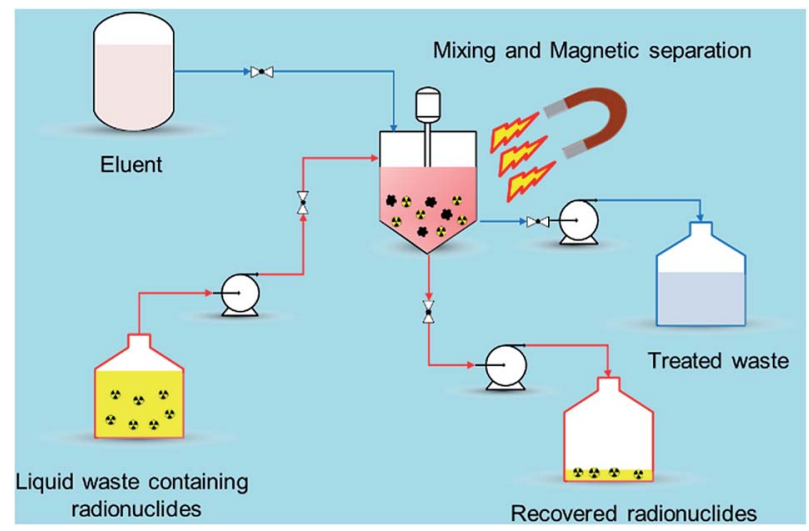

Fig. 2 Magnetic assisted separation for radionuclides from wastewater.

a relatively short time right after collecting the MNPs using a magnet (or magnetic system). In comparison to conventional adsorbents, the radionuclides adsorbed on the MNPs can easily be tracked, retrieved, and reused with the aid of magnetic field which reduces the secondary pollution and protect the public especially during accidental release of radionuclides to the environment. i.e., Fukushima, Chernobyl etc. Eventually, the final waste containing the concentrated radionuclides can be disposed of permanently in a safe storage area.

MNPs composed of magnetic metals include $\mathrm{Fe}, \mathrm{Ni}$, Co, and their oxides. Among these, magnetite $\left(\mathrm{Fe}_{3} \mathrm{O}_{4}\right)$ nanoparticles (mNPs), one of the most widely used magnetic materials, has gained immense attention due to its strong magnetic susceptibility, cost effectiveness, and biocompatibility. Owing to these exceptional features, m-NPs have a wide variety of application in diverse research disciplines such as magnetic resonance imaging, catalysis, separation, and environmental remediation. In the field of environmental remediation, several reviews have been documented on the removal of heavy metals, ${ }^{20}$ pesticides, ${ }^{21}$ and other emerging organic contaminants. ${ }^{22}$ Meanwhile, Maninder Kaur et al. studied the chelation processes of MNPs for the removal of minor actinides from spent nuclear fuel and demonstrated the design of effective processes. ${ }^{23}$ The reviews on the magnetite-based adsorbents for use in radioactive waste management is less well documented. This review aimed to bridge the knowledge gaps and to document essential researches in the field by presenting the recent decontamination studies of radionuclides by magnetite-based adsorbents, including their synthesis, and adsorption behavior of radionuclides between the adsorbent interfaces under diverse experimental conditions. In addition, case studies for the removal of radionuclides from real environmental samples were summarized to provide basic knowledge for optimizing their application in real-world remediation problems.

\section{Synthesis of magnetite-based adsorbents}

In the recent years, magnetite has been synthesized by many different methods such as co-precipitation, ${ }^{24}$ electrochemical 
Table 1 Pros and cons of different preparation methods for magnetite nanoparticles

\begin{tabular}{|c|c|c|c|}
\hline Method & Pros & Cons & Ref. \\
\hline Co-precipitation & $\begin{array}{l}\text { Economical precursors } \\
\text { Mild reaction conditions } \\
\text { Synthesis in } \mathrm{H}_{2} \mathrm{O} \\
\text { Ease surface modification } \\
\text { Short synthesis time minutes per } \\
\text { hours } \\
\text { Ease formation of ferrites } \\
\text { Ease conversion to g- } \mathrm{Fe}_{2} \mathrm{O}_{3} \\
\text { Ease scale-up }\end{array}$ & $\begin{array}{l}\text { Broad size distribution } \\
\text { Low reproducibility } \\
\text { Uncontrolled oxidation }\end{array}$ & 24 \\
\hline Reverse micelle & $\begin{array}{l}\text { Improved size control } \\
\text { narrow size distribution } \\
\text { Ease size tunability } \\
\text { Uniform magnetic properties }\end{array}$ & $\begin{array}{l}\text { Low reaction yield } \\
\text { Poor crystallinity } \\
\text { Surfactants are difficult to remove }\end{array}$ & 26 \\
\hline Hydrothermal reaction & $\begin{array}{l}\text { Improved size control } \\
\text { - Narrow size distribution } \\
\text { Synthesis in } \mathrm{H}_{2} \mathrm{O} \\
\text { - Tunable magnetic properties }\end{array}$ & $\begin{array}{l}\text { High pressure and reaction } \\
\text { temperature } \\
\text { Safety of the reactants }\end{array}$ & 32 \\
\hline Thermal/sonochemical decomposition & 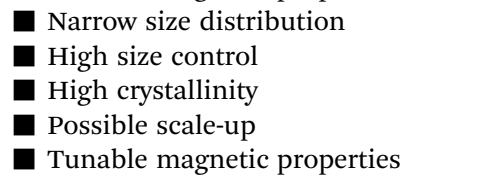 & $\begin{array}{l}\text { Toxic organic solvents used } \\
\text { High temperatures needed } \\
\text { Phase transfer required } \\
\text { Mechanism is still under discussion }\end{array}$ & 33 and 35 \\
\hline Sol-gel & $\begin{array}{l}\text { Moderate temperature conditions } \\
\text { Relatively short reaction period } \\
\text { Good shape control } \\
\text { Relatively narrow size distribution }\end{array}$ & $\begin{array}{l}\text { High pressure is required } \\
\text { Usually needs expensive precursors } \\
\text { High permeability } \\
\text { Low wear resistance } \\
\text { Weak bonding }\end{array}$ & 29 \\
\hline Biological & $\begin{array}{l}\text { High yield } \\
\text { [ Low production cost } \\
\text { Good reproducibility }\end{array}$ & Slow and laborious & 38 and 39 \\
\hline
\end{tabular}

deposition, ${ }^{25}$ synthesis in reverse micelles, ${ }^{26}$ combustion synthesis, ${ }^{27}$ mechano-chemical dispersion, ${ }^{28}$ sol-gel process, ${ }^{29}$ arc discharge, ${ }^{30}$ flow injection synthesis, ${ }^{31}$ hydrothermal, ${ }^{32}$ thermal decomposition, ${ }^{33}$ solvothermal, ${ }^{34}$ sonolysis, ${ }^{35}$ hightemperature annealing, ${ }^{36}$ and micro-emulsions. ${ }^{37}$ Features of these widely-adopted methods are presented in Table 1. Among the various synthesis routes, thermal decomposition as well as hydrothermal methods are found to be two of the most ideal ones based on particle size and well controlled morphology. In terms of biocompatibility and water solubility of m-NPs, coprecipitation method is frequently used but certain disadvantage such as uncontrolled shape, narrow size distribution, and aggregation of the particles could be associated for some applications. Some researchers have developed green/biological methods for the synthesis of m-NPs using seaweeds ${ }^{38}$ and microorganisms. ${ }^{39}$

\section{Classification of magnetite-based adsorbents}

Pristine m-NPs containing the magnetic core are highly susceptible to aggregation that causes significant changes in magnetic properties. Moreover, m-NPs are prone to undergo autoxidation and potential $\mathrm{Fe}^{2+}$ leaching, and not well target- selective under ambient conditions. ${ }^{40}$ One elegant way of compensating for this problem involves modification of the magnetic core with the deposition of suitable chemical compounds which act as a protecting shell (Table 2). For its effective application to diverse contaminated sites, the chemical compounds for the m-NPs shell may be organic (e.g., polymers and surfactants) or inorganic (e.g., silica, carbon, and noble metals). As a result of proper modification, the resulting m-NPs exhibit higher stability and adsorption capacity by preventing potential oxidation and aggregation. In addition, the protecting chemical compounds can be further conjugated with various chelating agents, eventually making m-NPs a more versatile precursor for a broad range of environmental applications. Besides the surface modification or functionalization of m-NPs, an alternative approach can be achieved by in situ encapsulation of m-NPs with different substrate materials (porous carbonaceous materials, inorganic clay, etc.) to synthesize magnetically retrievable composites (Table 3). The resulting magnetic composites show remarkable performance for radionuclides removal which is simply unattainable by individual substrate components. Moreover, another strategy is to prepare magnetic polymer beads with homogeneously distributed m-NPs. Herein, $\mathrm{m}$-NPs are dispersed in a in a polymeric solution and emulsified as a disperse phase. Then each droplet of the emulsion is 


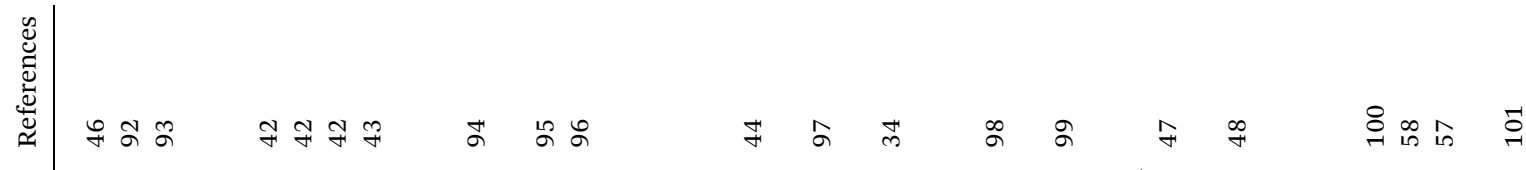

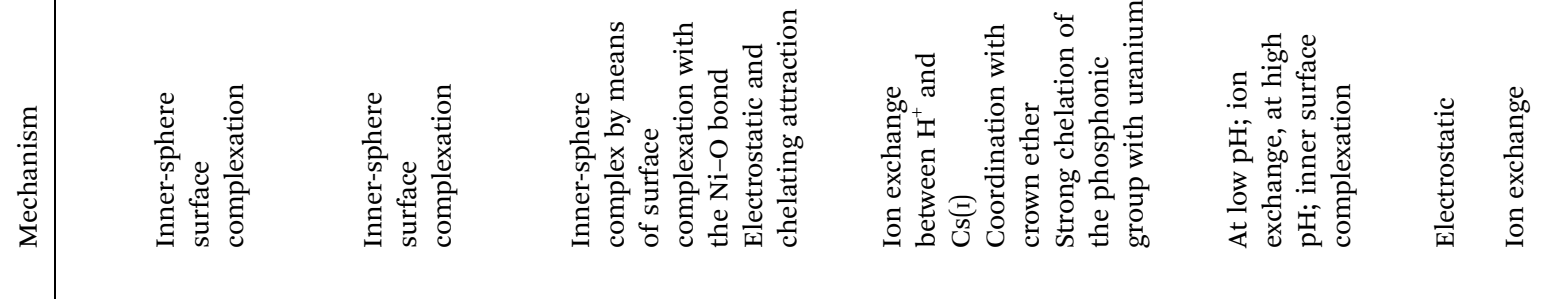

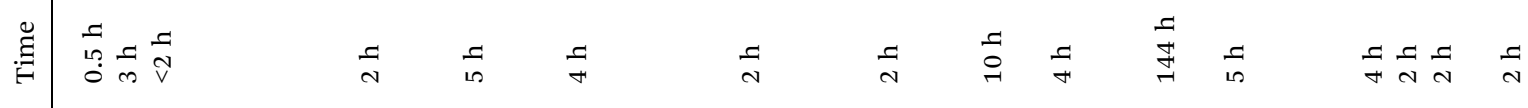

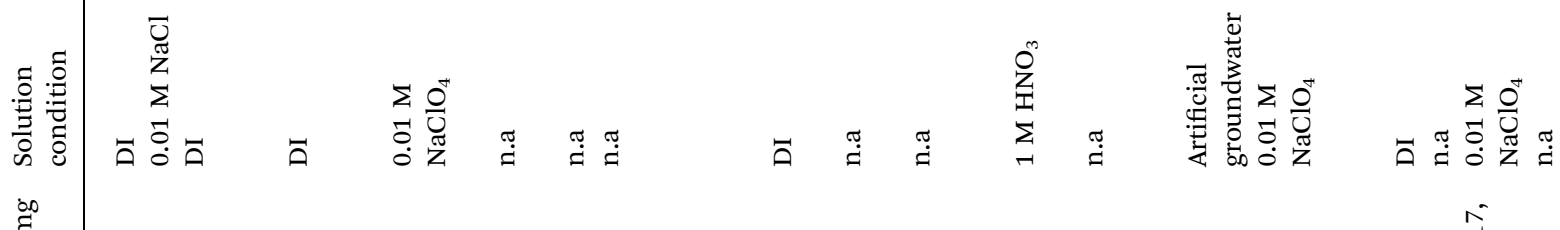

$\stackrel{\text { ڤ્ }}{\mathrm{g}}$

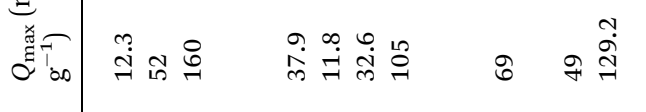

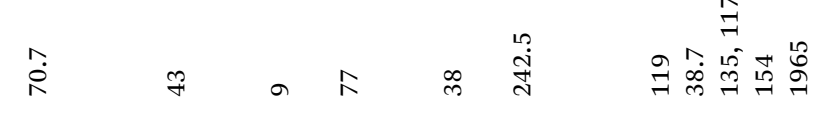

焉

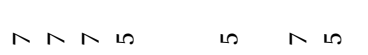

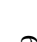

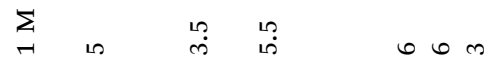

छ్

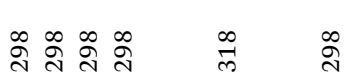

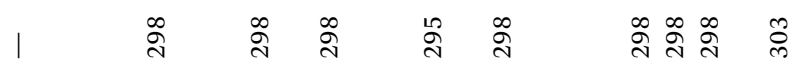

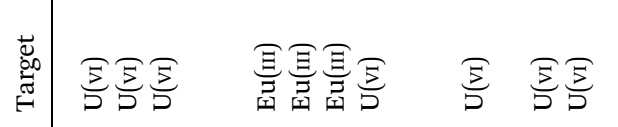

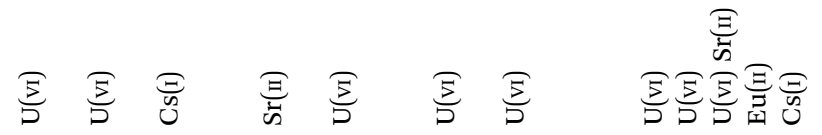

言

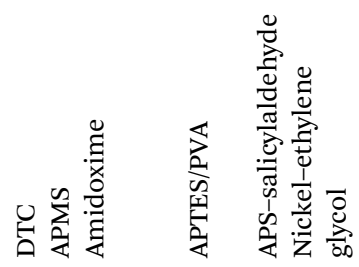

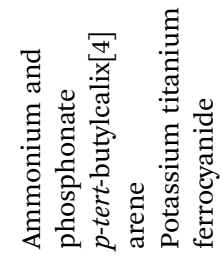

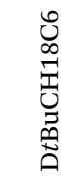

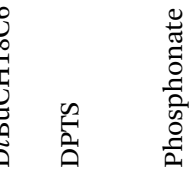

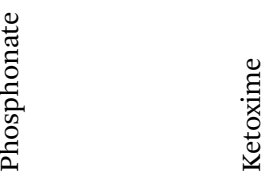

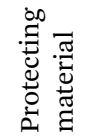

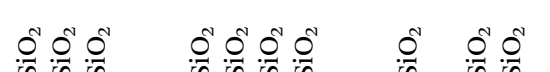

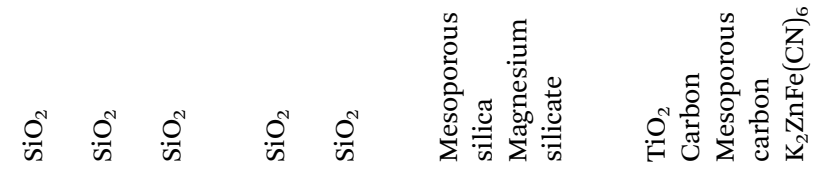

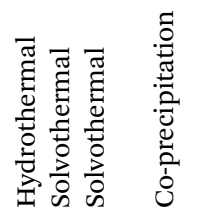




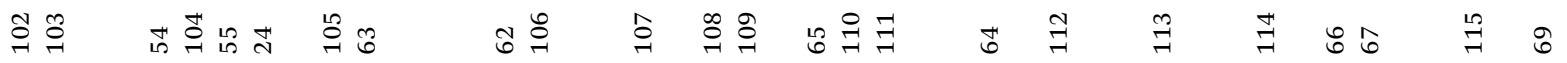

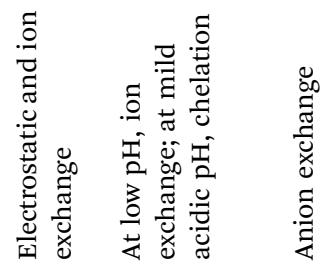

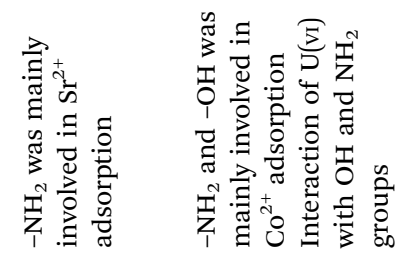

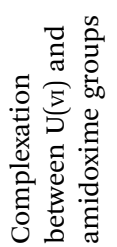

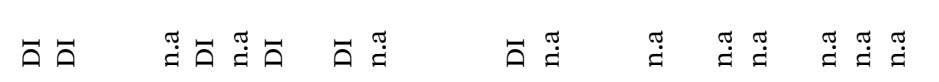

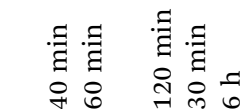

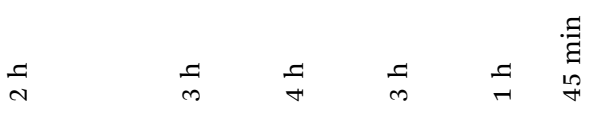

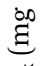

है.

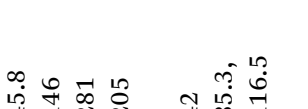

$\infty$

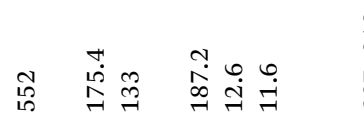

空

$\sum_{0}^{\infty} 0_{0}^{+}$

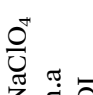

(1)

胥

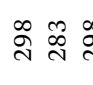

잉

o̊

文

$\stackrel{\infty}{\infty}$

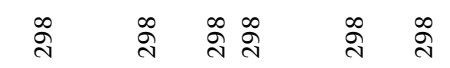

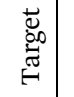
퓽큠 퓽풍퓽융
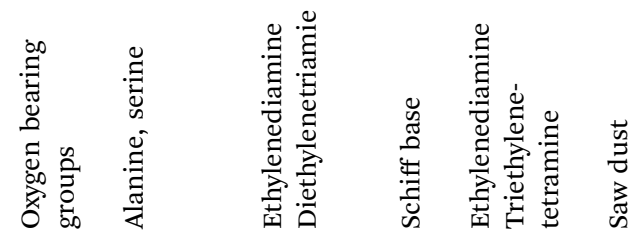

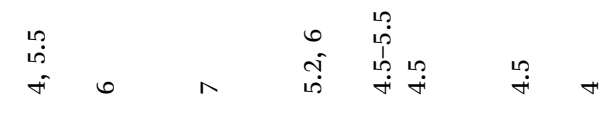

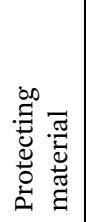

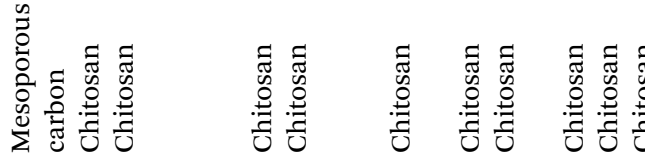
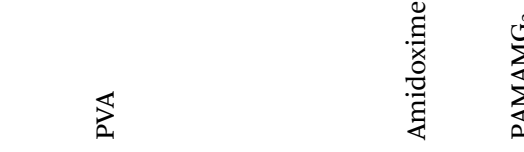

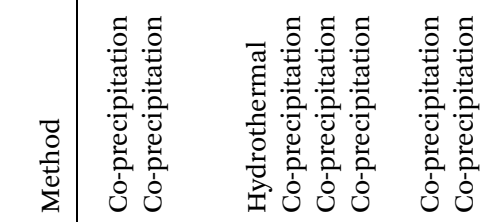
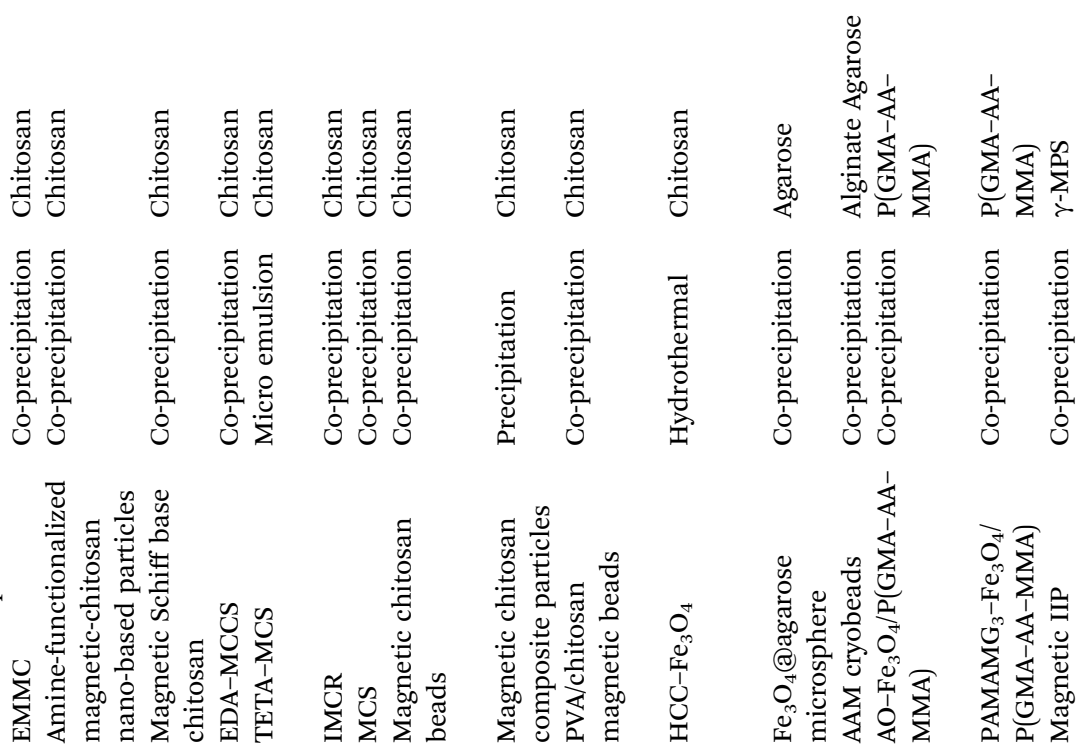


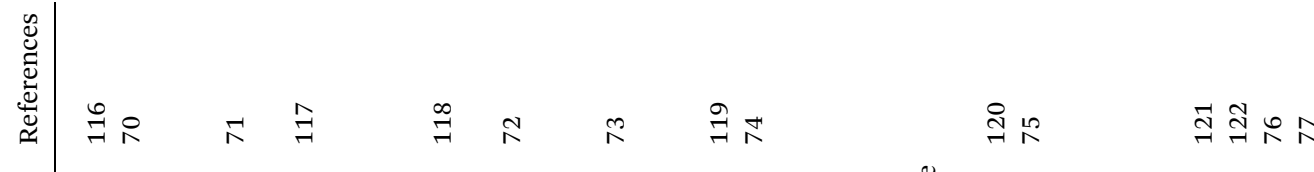

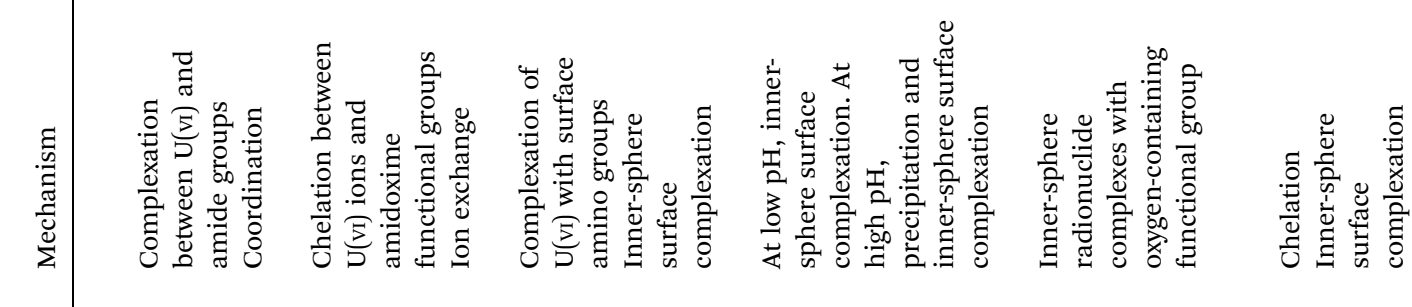

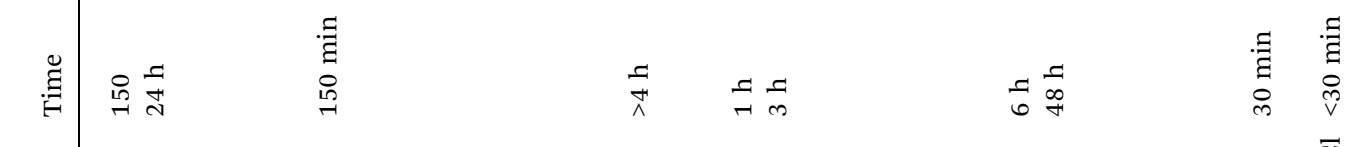

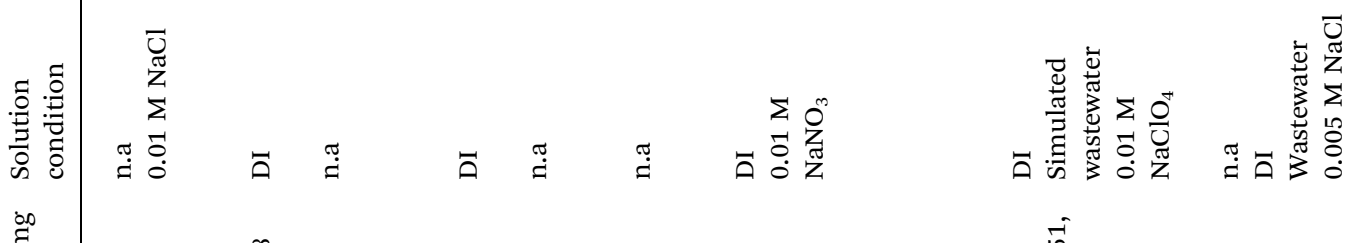

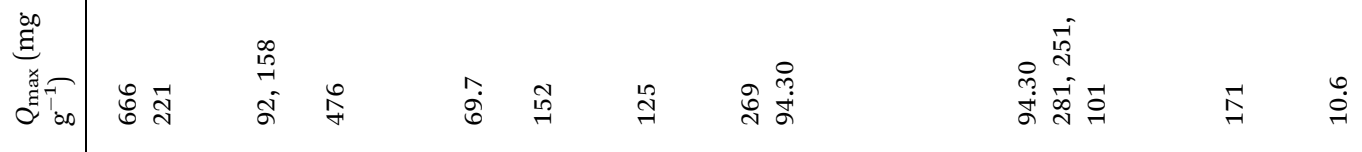

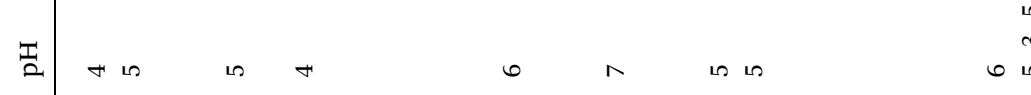

离

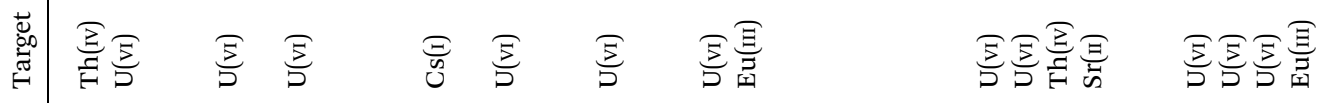

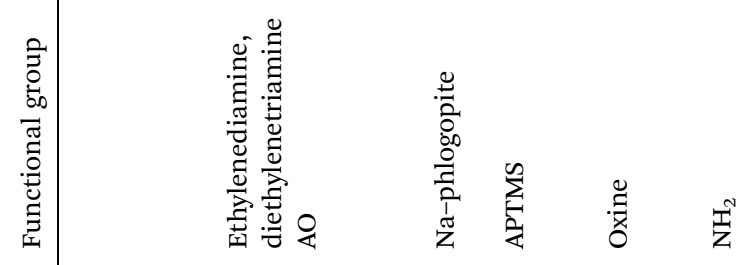

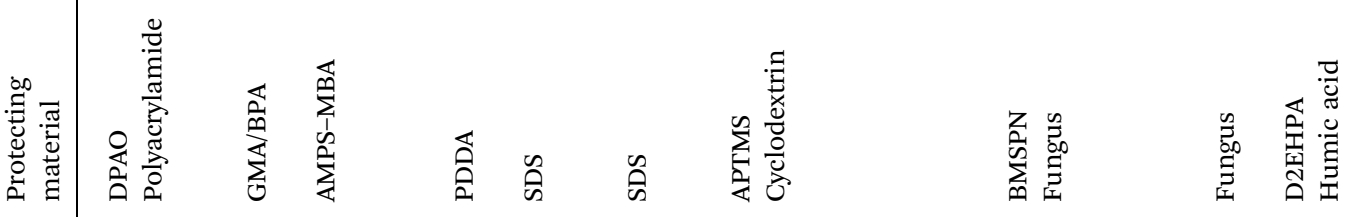

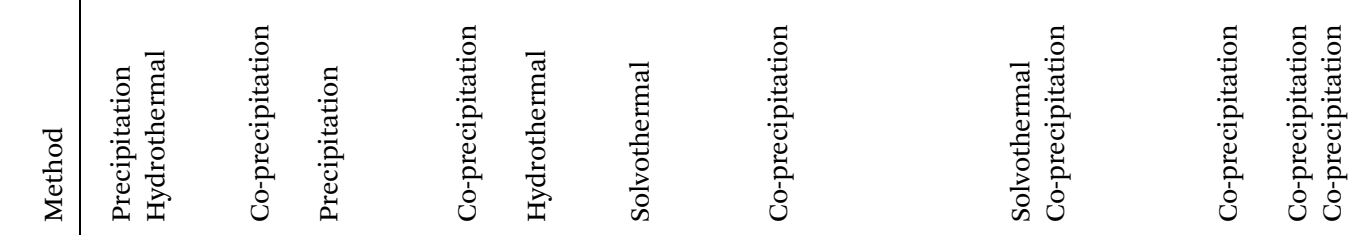

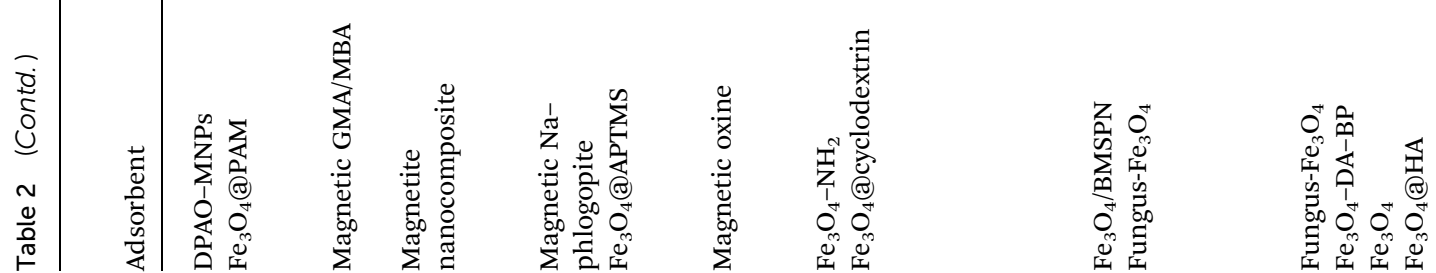


赵

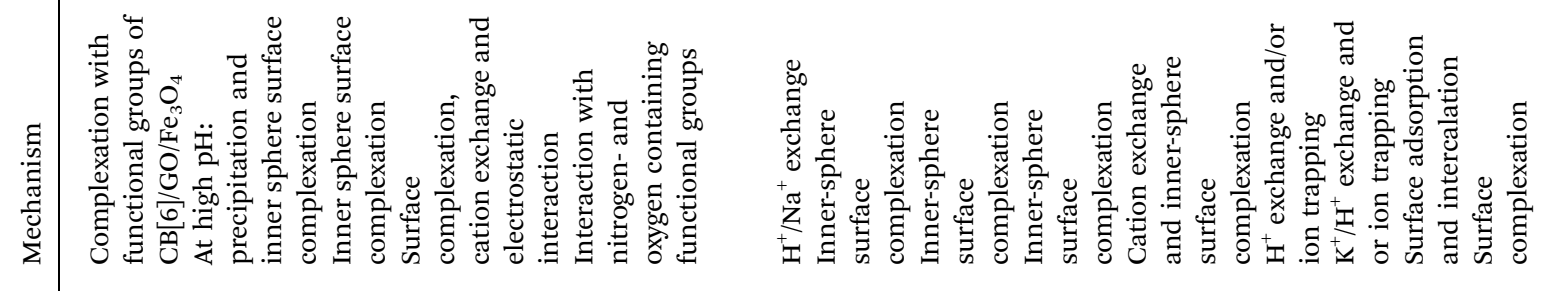

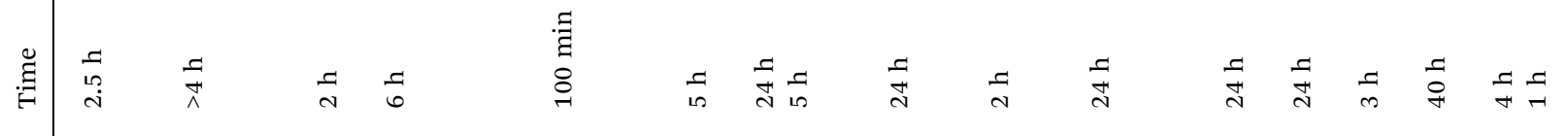

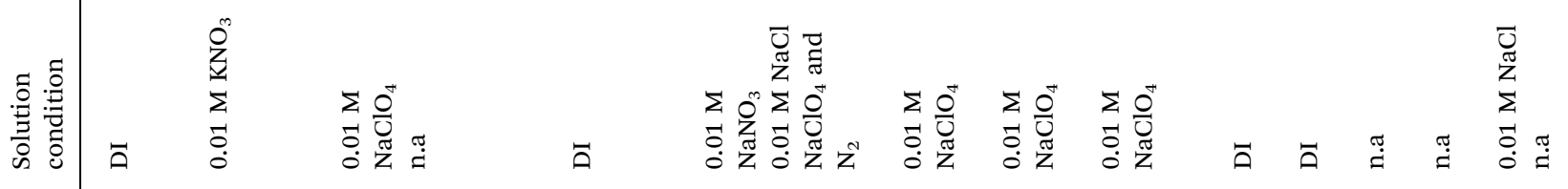

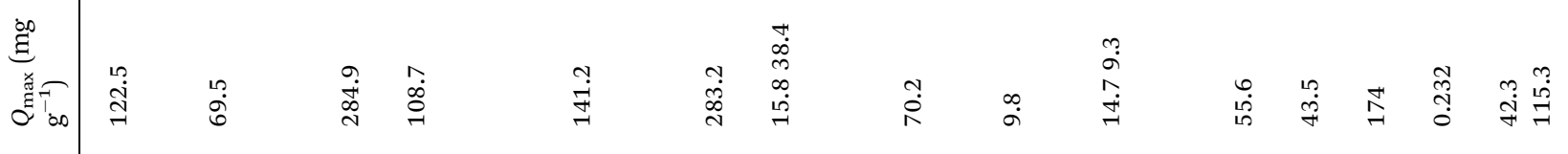

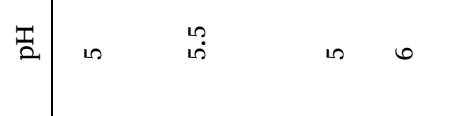

is

is 1

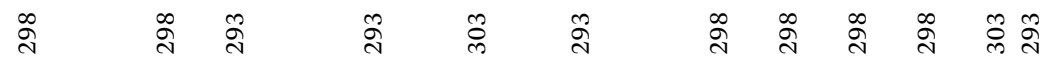

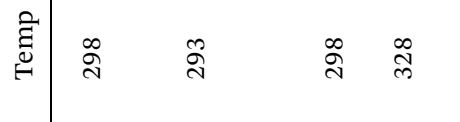

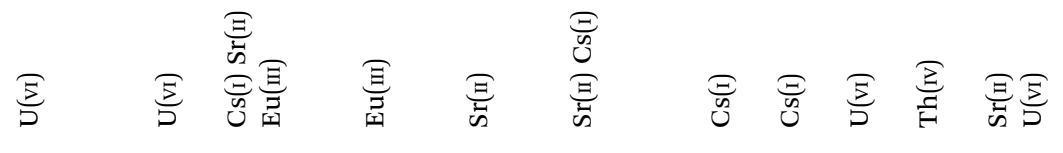

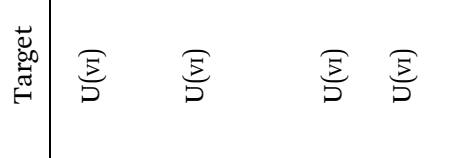

萓

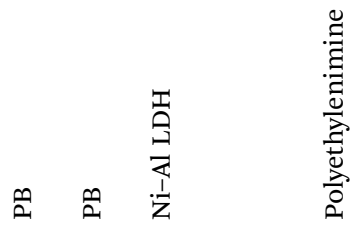

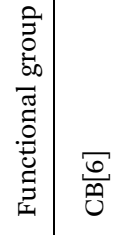

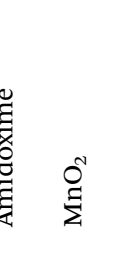

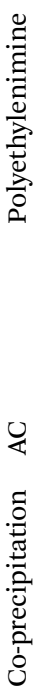

迎

空

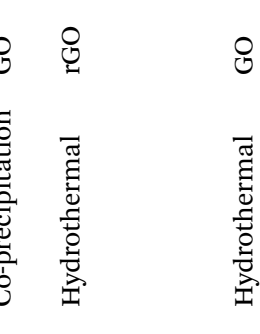

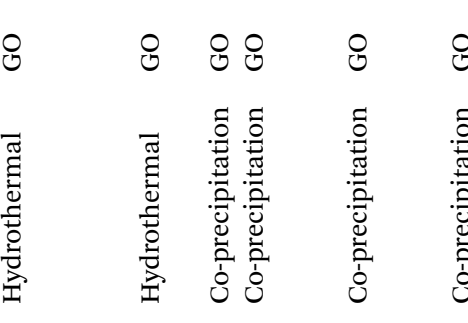

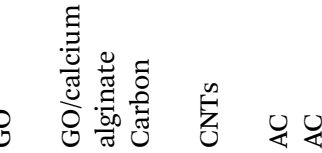

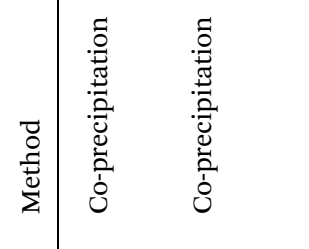

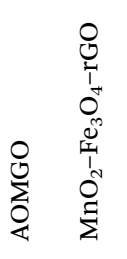

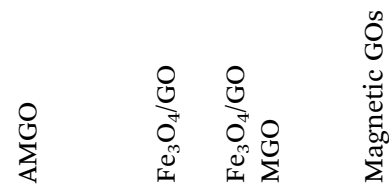

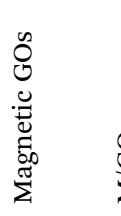

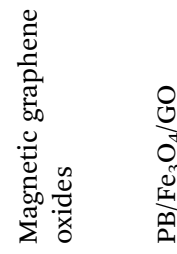

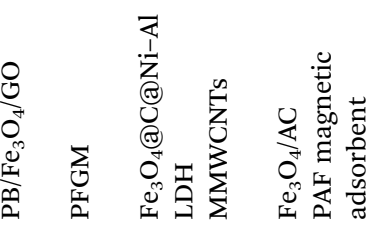




\section{RSC Advances}

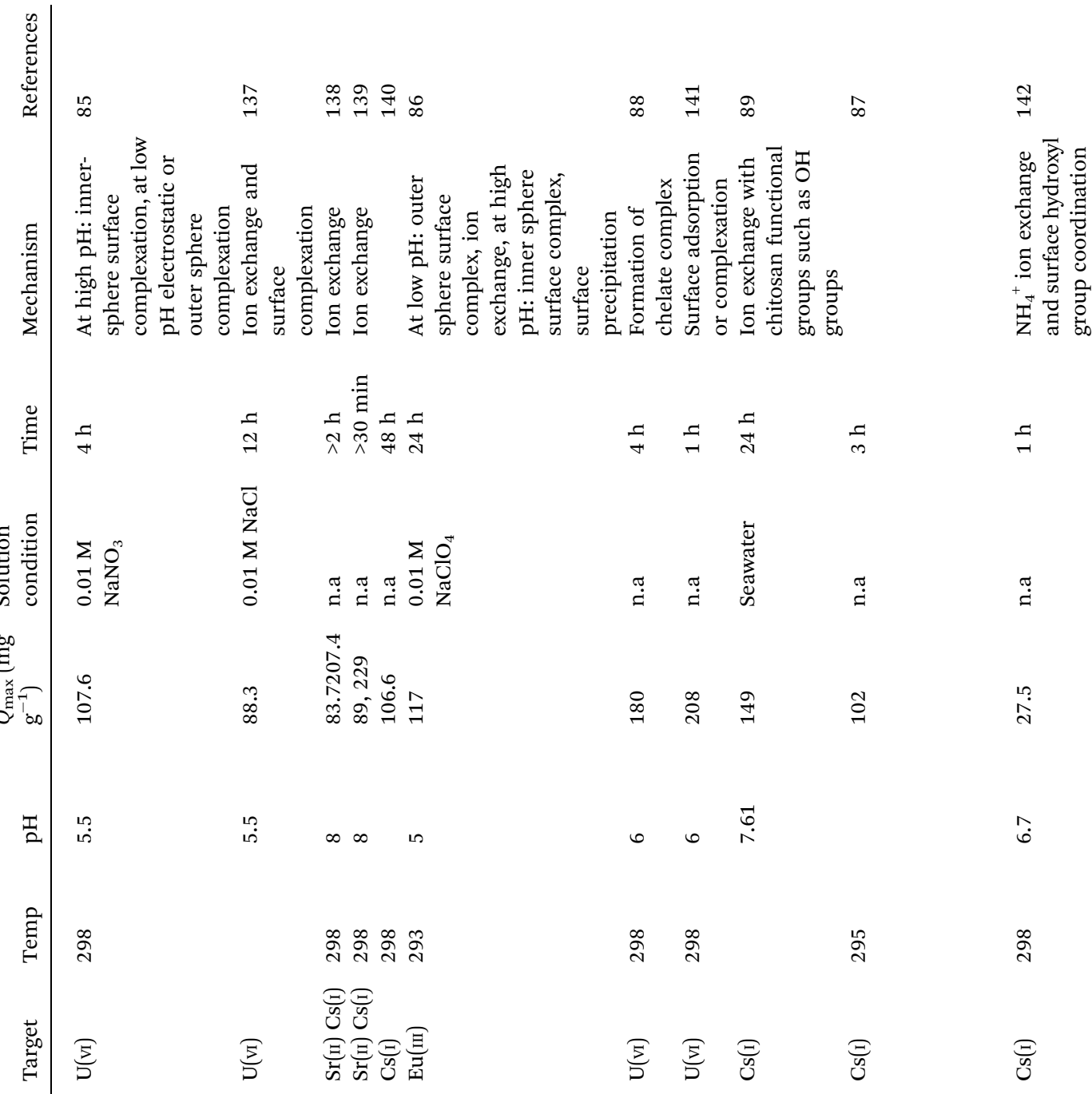

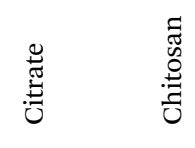

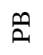
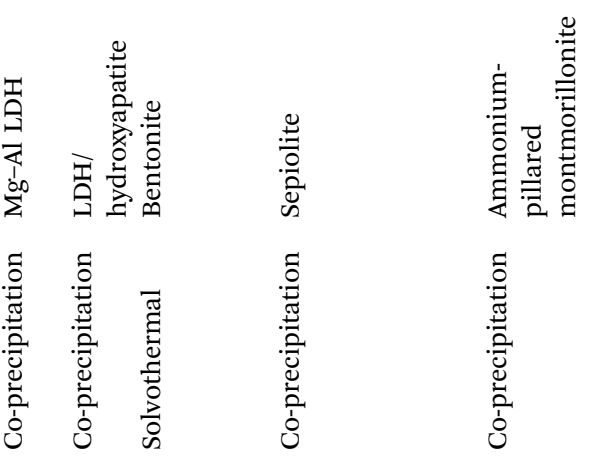

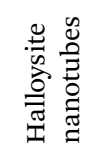
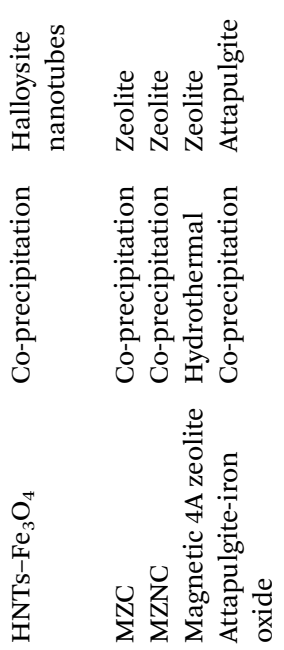

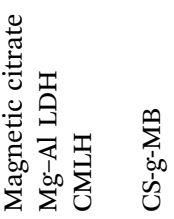

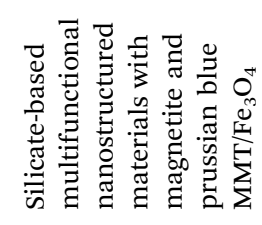




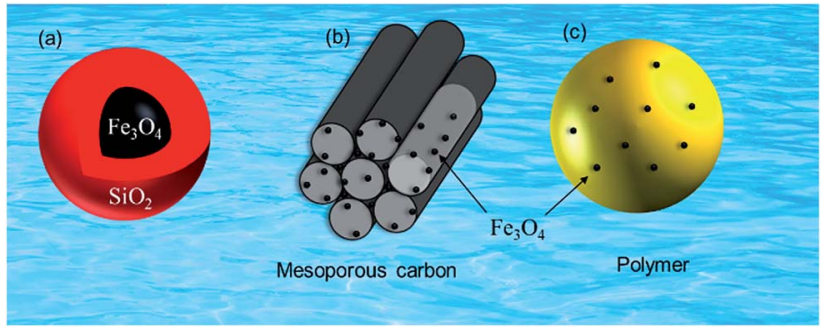

Fig. 3 Magnetite-based adsorbents (a) silica protected magnetite, (b) mesoporous carbon supported magnetite and (c) magnetite embedded polymer.

transformed into bead either by cross-linking or evaporation. ${ }^{\mathbf{4 1}}$ To date, magnetite-based composites have been fabricated with polymers, carbonaceous materials, biomaterials, and inorganic oxides for the enhanced removal of radionuclides (Fig. 3). Consequently, magnetite adsorbents can be categorized according to type of shell as well as type of porous substrate as given below (Fig. 4):

\subsection{Surface coated magnetite-based adsorbents}

\subsubsection{Inorganic coating}

3.1.1.1 Silica coating. Surface protection of the magnetite particles by a silica layer is the most commonly-employed method due to several advantages including chemical and colloidal stabilities, low cost, and controlled porosity. ${ }^{23}$ In addition, the terminal $\mathrm{OH}$ groups on the silica surface can be easily functionalized with various organic and inorganic moieties with respect to selective removal of metals. Silica coating can be achieved through Stober process via sol-gel reaction which involves the use of tetraethyl orthosilicate (TEOS) in acidic and/or basic $\mathrm{pH}$ conditions under vacuum. Several works have been reported in the literatures demonstrating the effective use of silica protected m-NPs grafted with various functional groups for the removal of radionuclides, ${ }^{\mathbf{4 2 , 4 4}}$. However, the - $\mathrm{Si}-\mathrm{O}-\mathrm{Si}-$ bond in silica coating is susceptible to rapid degradation in basic conditions resulting in significant loss of surface-grafted functional groups.

A comparison study of Eu(III) adsorption was conducted with four different types of magnetic adsorbent materials including bare magnetite $\left(\mathrm{Fe}_{3} \mathrm{O}_{4}\right)$, silica-coated magnetite $\left(\mathrm{Fe}_{3} \mathrm{O}_{4} @ \mathrm{SiO}_{2}\right)$, and silica-coated magnetite with surfaces functionalized with amine groups $\left(\mathrm{Fe}_{3} \mathrm{O}_{4} @ \mathrm{SiO}_{2} / \mathrm{APMS}\right)$ and dithiocarbamate groups $\left(\mathrm{Fe}_{3} \mathrm{O}_{4} @ \mathrm{SiO}_{2} / \mathrm{DTC}\right) .{ }^{42}$ As a result of subsequent modification, the net surface charge was significantly varied from 2.2 to $-44 \mathrm{mV}$. These materials adsorbed $\mathrm{Eu}$ in the order of $\mathrm{Fe}_{3}$ $\mathrm{O}_{4} @ \mathrm{SiO}_{2} \approx \mathrm{Fe}_{3} \mathrm{O}_{4} @ \mathrm{SiO}_{2} / \mathrm{APMS}>\mathrm{Fe}_{3} \mathrm{O}_{4}>\mathrm{Fe}_{3} \mathrm{O}_{4} @ \mathrm{SiO}_{2} /$ DTC at pH 7 in DI water; higher adsorption was due to the preferred coordination of $\mathrm{Eu}(\mathrm{III})$ with the $\mathrm{O}$ donors. The Eu adsorption was lower in $\mathrm{Fe}_{3} \mathrm{O}_{4} @ \mathrm{SiO}_{2} /$ DTC because of insufficient accessible $\mathrm{O}$ donating ligands than bare $\mathrm{Fe}_{3} \mathrm{O}_{4}$.

Magnetic adsorbents comprising of magnetic core protected with silica shell and amidoxime as a functional group were synthesized and investigated to extract uranium from aqueous solutions. ${ }^{43}$ In comparison with raw silica coated magnetite $\left(\mathrm{Fe}_{3} \mathrm{O}_{4} @ \mathrm{SiO}_{2}\right)$, the prepared $\mathrm{Fe}_{3} \mathrm{O}_{4} @ \mathrm{SiO}_{2}-\mathrm{AO}$ exhibited better adsorption capability due to the strong complexation of $\mathrm{U}(\mathrm{vI})$ with amidoxime moieties. The maximum adsorption capacity obtained by this adsorbent was $105 \mathrm{mg} \mathrm{g}^{-1}$ at pH 5 in $0.01 \mathrm{M}$ $\mathrm{NaClO}_{4}$ solution. For the $\mathrm{pH}$ values below 3, retention capacity significantly dropped, which meant that the adsorbed $\mathrm{U}(\mathrm{vI})$ could be desorbed under acidic conditions. For this reason, the stability of adsorbent was assured by dispersing the adsorbent in hydrochloric acid solution in the concentration range of 0.01-2 $\mathrm{mol} \mathrm{L}^{-1}$ up to 2 weeks and then a regeneration study was performed where the adsorbent was used for six consecutive runs with only a $6.2 \%$ decline in adsorption efficiency. In addition to good stability and better adsorption capacity, the adsorption process was rapid and reached the equilibrium within $2 \mathrm{~h}$.

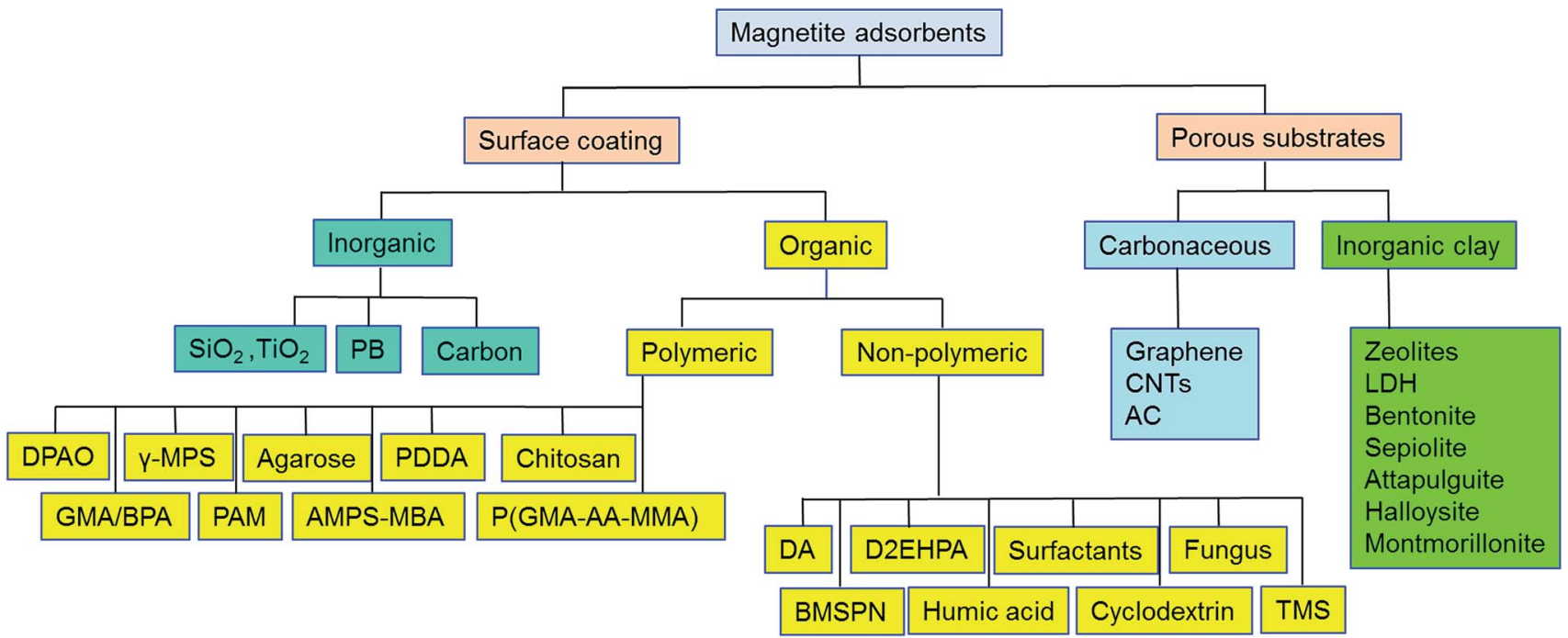

Fig. 4 Classification of magnetite-based adsorbents for removal of radionuclides. 
Post-synthesis grafting method was adopted to prepare a magnetic adsorbent bi-functionalized with ammonium and phosphonate groups for the removal of $\mathrm{U}(\mathrm{vI})$ in an alkaline environment ${ }^{44} 5$. The combination of dual functionalities enhanced adsorption performance and maximum $\mathrm{U}(\mathrm{vI})$ uptake capacity was $70.7 \mathrm{mg} \mathrm{g}^{-1}$ at $\mathrm{pH} 9$ in DI water due to electrostatic attraction between $\mathrm{NH}_{4}{ }^{+}$and $\left(\mathrm{UO}_{2}\right)_{3}(\mathrm{OH})_{7}{ }^{-}$, and complexation between phosphonate and $\mathrm{U}(\mathrm{vI})$. Unlike $\mathrm{NO}_{3}{ }^{-}$and $\mathrm{SO}_{4}{ }^{2-}$ anions, the presence of $\mathrm{PO}_{4}{ }^{3-}$ as a co-existing anion inhibited the adsorption process due to possible complexation between $\mathrm{U}(\mathrm{vI})$ and dissociated $\mathrm{PO}_{4}{ }^{3-}$. Considering the minute $\mathrm{U}(\mathrm{vI})$ adsorption at $\mathrm{pH} 4$, the adsorbent was renewed with $0.2 \mathrm{~mol} \mathrm{~L}^{-1}$ $\mathrm{HNO}_{3}$ for six cycles where the U(vI) recovery decreased from $97.1 \%$ to $90.4 \%$.

Quercetin $\left(3,3^{\prime}, 4^{\prime}, 5,7\right.$-pentahydroxyflavone $)$ is a naturally occurring dietary flavonoid that has the ability to form stable complexes with transition metals ( $\mathrm{Fe}, \mathrm{Co}, \mathrm{Ni}, \mathrm{Cu}$, and $\mathrm{Zn}$ ). ${ }^{45} \mathrm{In}$ this context silica-coated $\mathrm{Fe}_{3} \mathrm{O}_{4}$ nanoparticles were modified with quercetin and employed as a adsorbent for the uptake of uranyl ions $\left(\mathrm{UO}_{2}{ }^{2+}\right)$ in spiked ground and commercial (Nestle) drinking mineral water samples. ${ }^{46}$ This adsorbent exhibited the maximum uptake capacity of $12.3 \mathrm{mg} \mathrm{g}^{-1}$ at $\mathrm{pH} 5$ in DI water. In addition, the adsorption process was rapid and reached steady state within thirty minutes.

Li et $a l .{ }^{47}$ anchored various organic moieties including aminopropyl, benzoylthiourea (BT), dihydroimidazole (DIM), polyaryloamidoxime (AD), phosphonate (PP), phosphonate-amino (PPA), chloropropyl, poly(propylenimine) (PPI), and poly(amidoamine) (PAMAM) into mesopores of thickness $3 \mathrm{~nm}$ of magnetic mesoporous silica particles (MMSNs) and explored the reactivity of each functionalized adsorbent towards uranium in low and high $\mathrm{pH}$ artificial groundwater. Under the acidic conditions ( $\mathrm{pH}$ 3.5), MMSNSs-PP was found to be the best adsorbent with highest $\mathrm{U}(\mathrm{vI})$ adsorption capacity $(37.5 \mathrm{mg}$ $\mathrm{g}^{-1}$ ). However, in alkaline conditions ( $\mathrm{pH} 9.6$ ), MMSNs-PPI exhibited the highest $\mathrm{U}(\mathrm{vI})$ adsorption capacity (133.3 $\mathrm{mg} \mathrm{g}^{-1}$ ).

Yolk-shell microspheres with $\mathrm{Fe}_{3} \mathrm{O}_{4}$ cores and hierarchical magnesium silicate shells $\left(\mathrm{Fe}_{3} \mathrm{O}_{4} @ \mathrm{MS}\right)$ have been successfully synthesized by combining the versatile sol-gel process and hydrothermal reaction in which, $\mathrm{Fe}_{3} \mathrm{O}_{4} @ \mathrm{SiO}_{2}$ served as a chemical template. ${ }^{48}$ The as prepared $\mathrm{Fe}_{3} \mathrm{O}_{4} @ \mathrm{MS}$ microspheres were assessed as a potential adsorbent for $\mathrm{U}(\mathrm{vI})$ removal from water. The $\mathrm{U}(\mathrm{vI})$ adsorption on $\mathrm{Fe}_{3} \mathrm{O}_{4} @ \mathrm{MS}$ microspheres was strongly dependent on $\mathrm{pH}$ and the ionic strength. The maximum adsorption capacity for $\mathrm{U}(\mathrm{vI})$ was calculated to be $242.5 \mathrm{mg} \mathrm{g}^{-1}$ at pH 5.5 in $0.01 \mathrm{M} \mathrm{NaClO}_{4}$ solution. The thermodynamic analysis revealed that the adsorption of $\mathrm{U}(\mathrm{vI})$ onto $\mathrm{Fe}_{3} \mathrm{O}_{4} @ \mathrm{MS}$ was spontaneous and endothermic. In addition, the adsorption of $\mathrm{U}(\mathrm{vI})$ was dominated by ion exchange at low $\mathrm{pH}$ conditions, but by the inner-sphere surface complex at high $\mathrm{pH}$ $(>6)$.

Among the various radionuclides, Tc is comparatively a less studied radionuclide due to difficulty in removing high mobile Tc in the environment. To prevent migration of Tc, most Tcbearing radioactive waste should be solidified using waste form like glass. However, at glass vitrification temperatures $\left(\sim 1200^{\circ} \mathrm{C}\right)$, Tc is rapidly volatilized resulting in the substantial loss of Tc from the final waste glass. Recently scientists found that addition of magnetite as an additive during the vitrification process significantly improved the Tc retention in glass waste form, where it is incorporated in the octahedral sub-lattice provided by magnetite. ${ }^{\mathbf{4 9 5}}$ In addition, quantum-mechanical modeling techniques were used to demonstrate incorporation energies and optimized lattice bonding environments for charge-balanced $\mathrm{Tc}(\mathrm{Iv})$ incorporation mechanisms in magnetite. ${ }^{49}$

3.1.1.2 Prussian blue coating. Prussian blue (PB) is a low-cost cyano-bridged coordination polymer containing hexacyanometallates and transition metal ions with chemical formula $\mathrm{Fe}_{7}(\mathrm{CN})_{18}$. It has been used as an antidote for patients contaminated with radioactive cesium since the Chernobyl nuclear accident in 1986. The high binding selectivity arises from size compatibility of hydrated cesium ion with the cage size of the PB lattice. ${ }^{51}$ This is why a majority of studies are based on the Prussian blue nanoparticles (PB-NPs) for cesium decontamination from the actual environmental samples including seawater and soil. However, the Cs ions are incorporated in PB lattice structure therefore, it is not easy for the PBNPs to be regenerated. In addition, the use of PB-NPs and its analogues might be problematic at high $\mathrm{pH}$ due to leaching of cyanide ions. More importantly, the retrievability of Cs loaded PB-NPs is a hurdle in the real field applications. Sasaki and Tanaka $^{52}$ reported the synthesis of Prussian-blue-modified magnetite $\left(\mathrm{PB}-\mathrm{Fe}_{3} \mathrm{O}_{4}\right)$ through a scalable co-precipitation method for the decontamination of aqueous Cs. Consequently, the maximum adsorption amount of Cs with $\mathrm{PB}-\mathrm{Fe}_{3} \mathrm{O}_{4}$ was $16.2 \mathrm{mg} \mathrm{g}^{-1}$ and the adsorption capacity was not greatly influenced in the presence of high concentration of $\mathrm{NaCl}$ solution. Thammawong et $a .^{53}$ developed magnetic nanoadsorbent using a facile chemical co-precipitation of ferric and ferrous salts to firstly obtain the MNP cores, which are further reacted with $\left[\mathrm{Fe}(\mathrm{CN})_{6}\right]^{4-}$ under acidic conditions to produce a coating of the PB layer onto the MNPs. The adsorbent possessed both high Cs adsorption capacity (96 mg Cs $\mathrm{g}^{-1}$ adsorbent) and large distribution coefficient, $K_{\mathrm{d}}\left(3.2 \times 10^{4} \mathrm{~mL}\right.$ $\mathrm{g}^{-1}$ at $0.5 \mathrm{ppm}$ Cs in DI water). The magnetic adsorbent was proposed to use as a new type of Cs decorporation drug for Cs contaminated patients.

Later, Yang et $a .^{54}$ fabricated the Prussian bluefunctionalized magnetic nanoclusters (PB-MNC) by hydrothermal method without addition of coating materials such as PDDA, to provide much higher saturation magnetization (27.5 emu $\mathrm{g}^{-1}$ ) and to coat large quantities of $\mathrm{PB}$ on the surface of the MNC. As a result, PB-MNC had a large Cs distribution coefficient, even in the presence of $3000 \mathrm{ppm}$ competing ions such as $\mathrm{K}^{+}, \mathrm{Na}^{+}, \mathrm{Ca}^{2+}$, and $\mathrm{Mg}^{2+}$, and excellent removal efficiency $(>99.7 \%)$ of radioactive cesium from contaminated water.

Recently, magnetite $\mathrm{PB}$ adsorbent was synthesized by binding $\mathrm{PB}$ to a core of magnetite $\left(\mathrm{Fe}_{3} \mathrm{O}_{4}\right)$ nanoparticles for highly efficient and rapid separation of Cs from aqueous solution. ${ }^{55}$ The adsorbent showed a maximum Cs adsorption capacity of $280.82 \mathrm{mg} \mathrm{g}^{-1}$ at an initial Cs concentration of $50 \mathrm{mM}$ at $\mathrm{pH} 7$, and $10^{\circ} \mathrm{C}$, which is much higher than those of previously reported $\mathrm{PB}$-based adsorbents for removing Cs from 
the various solution. The higher adsorption capacity was positively correlated with large surface area of $322.2 \mathrm{~m}^{2} \mathrm{~g}^{-1}$ of the magnetite-PB nanocomposite.

3.1.1.3 Carbon coating. Carbon-coated magnetite nanoparticles are of great significance due to their better stability for an oxidative degradation as compared to silica coating. There are various approaches including chemical vapor deposition (CVD), pyrolysis, and detonation-induced reaction for the carbon coating. ${ }^{56}$ The main advantage of CVD is the precise control on the thickness of carbon coating but this require high cost due to the need to use complex equipment and high energy consumption. On the other hand, the pyrolysis approach is an attractive option due to bulk production of carbon coated nanomaterials.

Hollow $\mathrm{Fe}_{3} \mathrm{O}_{4}$ magnetite nanoparticles coated with mesoporous carbon ( $\left.\mathrm{h}-\mathrm{Fe}_{3} \mathrm{O}_{4} @ \mathrm{mC}\right)$ have been synthesized using silica nanospheres as the sacrificial matrix and investigated as possible adsorbent for removal of radionuclides. ${ }^{57}$ Effects of contact time, $\mathrm{pH}$, and initial concentrations on the interaction of h- $\mathrm{Fe}_{3} \mathrm{O}_{4} @ \mathrm{mC}$ with $\mathrm{U}(\mathrm{VI}), \mathrm{Eu}(\mathrm{III}), \mathrm{Co}$ (II), and $\mathrm{Sr}(\mathrm{II})$ have been studied. The dependence of adsorption on $\mathrm{pH}$ is relevant to both the surface properties of adsorbents and the relative distribution of radionuclides species in solutions. As a result of mesoporous structure, carboxyl-functionalized surface, and low density due to hollow cavity, h- $\mathrm{Fe}_{3} \mathrm{O}_{4} @ \mathrm{mC}$ shows efficient adsorption for radionuclides even in acidic solutions. The maximum adsorption capacities of $\mathrm{U}(\mathrm{VI}), \mathrm{Eu}(\mathrm{III}), \mathrm{Co}(\mathrm{II})$, and $\mathrm{Sr}(\mathrm{II})$ on $\mathrm{h}-\mathrm{Fe}_{3} \mathrm{O}_{4} @ \mathrm{mC}$ at $\mathrm{pH} 3.0$ in $0.01 \mathrm{M} \mathrm{NaClO}_{4}$ solution calculated from the Langmuir isotherm model were $0.566,1.013,0.860$, and $0.733 \mathrm{mmol} \mathrm{g}^{-1}$, respectively.

The synthesis of Ketoxime-functionalized carbon coated iron oxide $\left(\mathrm{Fe}_{3} \mathrm{O}_{4} @ \mathrm{C}-\mathrm{KO}\right)$ was conducted by Liu et al. ${ }^{58}$ for the removal of hexavalent uranium from water. The resulting magnetic adsorbent showed $\mathrm{U}(\mathrm{vI})$ adsorption capacity of $38.7 \mathrm{mg} \mathrm{g}^{-1}$ at pH 6 in DI water. The adsorption-desorption experiment was repeated for three cycles with $0.5 \mathrm{M} \mathrm{HCl}$ resulting in $>80 \%$ desorption efficiency.

Recently, Husnain et al. ${ }^{24}$ developed three magnetic mesoporous carbon adsorbents, i.e., $\mathrm{Fe}_{3} \mathrm{O}_{4}-\mathrm{O}-\mathrm{CMK}-3$, O-Fe-CMK-3 and $\mathrm{Fe}-\mathrm{O}-\mathrm{CMK}-3$ using co-precipitation, impregnation, and co-casting methods, respectively. These materials adsorbed Cs in the order of $\mathrm{Fe}_{3} \mathrm{O}_{4}-\mathrm{O}-\mathrm{CMK}-3>\mathrm{O}-\mathrm{Fe}-\mathrm{CMK}-3>\mathrm{Fe}-\mathrm{O}-\mathrm{CMK}-3$; higher adsorption was due to the presence of polar groups on the surface of the adsorbent. The $\mathrm{Fe}_{3} \mathrm{O}_{4}-\mathrm{O}-\mathrm{CMK}-3$ removed Cs effectively without leaching of $\mathrm{Fe}$, and could be collected within a few seconds by using a magnet. Transmission electron microscopy (TEM) analysis confirmed the formation of a $20 \mathrm{~nm}$ thick oxidized mesoporous carbon coating around the m-NPs. The adsorbent showed maximum Cs adsorption capacity of $205 \mathrm{mg} \mathrm{g}^{-1}$ at $\mathrm{pH} 6$ in DI water with good adsorption affinity even in the presence of high concentrations of interfering cations $\left(\mathrm{K}^{+}, \mathrm{Na}^{+}, \mathrm{Li}^{+}, \mathrm{Ca}^{2+}\right.$, and $\left.\mathrm{Sr}^{2+}\right)$. The Cs adsorption onto $\mathrm{Fe}_{3} \mathrm{O}_{4}-\mathrm{O}-\mathrm{CMK}-3$ was due to a synergistic effect of electrostatic interaction and ion exchange of $\mathrm{H}^{+}$for Cs. The $\mathrm{Fe}_{3} \mathrm{O}_{4}-\mathrm{O}-\mathrm{CMK}-3$ adsorbent was regenerated well, and could be used for six adsorption cycles, unlike existing PB containing magnetic adsorbents.

\subsubsection{Organic coating}

3.1.2.1 Polymeric coating. The presence of different functional groups $\left(\mathrm{COOH}, \mathrm{SO}_{4}{ }^{2-}, \mathrm{PO}_{4}{ }^{3-}\right)$ in polymers can be chemically linked or physically adsorbed on the surface of magnetite particles such that the polymers surround the magnetite particles with a protective layer. ${ }^{59}$ The thickness of the layer can be tuned by the solution $\mathrm{pH} .{ }^{60}$ Repulsive forces are generated due to this layer which balances the magnetic and the van der Waals attractive forces acting on the NPs. Because of this layer, particles are well dispersed in solution. However, in acidic solutions, this layer is rapidly deteriorated resulting in the leaching of the magnetic core. In addition, polymer layers are not stable at high temperatures.

Chitosan is a naturally abundant, low cost ecologically benign biopolymer. ${ }^{61}$ It can bind various metals due to the presence of a high percentage of amino $\left(\mathrm{NH}_{2}\right)$ groups which makes it a versatile adsorbent. Recently, ethylenediaminemodified magnetic chitosan (EMMC) complex was developed by Wang et $a l .{ }^{62}$ as a novel magnetic adsorbent for $\mathrm{U}(\mathrm{VI})$ removal. Infra-red (IR) analysis demonstrated that $\mathrm{Fe}_{3} \mathrm{O}_{4}$ particles were successfully bound by chitosan and more amino groups appeared in the EMMC samples. EMMC was found to be quite efficient at adsorbing uranyl ions in the $\mathrm{pH}$ range of 2 to 7 in DI water. Adsorption equilibrium was established within $30 \mathrm{~min}$, and the kinetic experimental data was in good agreement with those estimated by pseudo-second-order kinetic model, suggesting that the chemical adsorption was the rate-limiting step. The adsorption data could be best interpreted by the Sips model with a maximum adsorption capacity of $\sim 83 \mathrm{mg} \mathrm{U} \mathrm{g}^{-1}$. The EMMC could be regenerated by $0.1 \mathrm{M} \mathrm{NaOH}$ solution.

Another suitable modification concerns the synthesis of hybrid materials composed of a magnetic core with a chitosan coating that was functionalized by amino acids (alanine/serine) through crosslinking epichlorohydrin for the uranium recovery from dilute solutions. ${ }^{63}$ Both functionalized adsorbents efficiently captured uranyl at $\mathrm{pH}$ 3.6. The adsorption mechanism mainly included ion exchange of anionic uranyl-sulfate species including $\mathrm{UO}_{2}\left(\mathrm{SO}_{4}\right)_{2}{ }^{2-}$ and $\mathrm{UO}_{2}\left(\mathrm{SO}_{4}\right)_{3}{ }^{4-}$ at $\mathrm{pH}<3.6$, whereas chelation with amino groups and carboxylate groups at $\mathrm{pH}=$ 6.7. Based on the Langmuir model, the maximum $\mathrm{U}(\mathrm{vI})$ adsorption capacities were $85.3 \mathrm{mg} \mathrm{g}^{-1}$ and $116.5 \mathrm{mg} \mathrm{g}^{-1}$ for magnetic nano particles with alanine and serine functionalized chitosan, respectively. Due to poor stability of the chitosan biopolymer in acidic conditions, desorbing solution contained 0.5 M urea dissolved in slightly acidic aqueous solutions (few drops of $0.2 \mathrm{M} \mathrm{H}_{2} \mathrm{SO}_{4}, 2<\mathrm{pH}<3$ ). Consequently, after five successive cycles, adsorption efficiency was close to $93 \%$ for alanine-based adsorbent and 91\% for serine-based adsorbent.

Magnetic iron chitosan composite particles with $40 \mu \mathrm{m}$ average size were obtained by in situ procedure and investigated as an economical scavenger for the radioactive wastewater contaminated with $\mathrm{U}(\mathrm{vI})$ and $\mathrm{Th}(\mathrm{IV}) .{ }^{64}$ The results indicated that the magnetic composite had superior adsorption capacities for both uranyl ions (666.67 $\mathrm{mg} \mathrm{g}^{-1}$ at $\mathrm{pH} 4$ ) as well as for thorium ions (312.50 $\mathrm{mg} \mathrm{g}^{-1}$ at $\mathrm{pH} 5.5$ ) compared to other low-cost adsorbents reported in the literature. Although, saturated 
magnetization of the composite declined from 24 to $18 \mathrm{emu}^{-1}$ during the adsorption process. However, this value $\left(18 \mathrm{emu} \mathrm{g}^{-1}\right)$ was sufficient for magnetic separation and recovery of radionuclide loaded adsorbent. According to thermodynamic studies, the adsorption process was spontaneous and endothermic. In addition, both the radioactive cations could be recovered by acidic desorbing agents (hydrochloric acid and nitric acid).

A chemically cross-linked U(vI)-imprinted magnetic chitosan resin (IMCR) was synthesized by using the ion-imprinting method with $\mathrm{U}(\mathrm{vI})$ as a template and glutaraldehyde as a cross-linker, respectively. ${ }^{65}$ Moreover, the non-imprinting magnetic chitosan resin (NIMCR) was synthesized as a control. The monolayer adsorption capacity was $187.26 \mathrm{mg}$ $\mathrm{g}^{-1}$ for IMCR and $160.77 \mathrm{mg} \mathrm{g}^{-1}$ for NIMCR at pH 5.0 in DI water, respectively. The IMCR showed better adsorption capacity for the $\mathrm{U}(\mathrm{VI})$ removal than NIMCR due to more active adsorption sites resulting from a large number of size compatible cavities for uranyl ions by ion imprinting. Thermodynamic studies suggested that the adsorption process was spontaneous and exothermic. Finally, the U(vI) loaded resin could be regenerated for repeated use with $0.5 \mathrm{M} \mathrm{HNO}_{3}$.

The novel development of alginate-agarose-magnetite cryobeads by the process of cryotropic-gelation at subzerotemperature was carried out for the recovery of hexavalent uranium from the aqueous sub-surfaces. ${ }^{66}$ Due to high interconnected porosity ( $\sim 90 \%)$, these cryo-beads exhibited lower density resulting in their excellent floating ability in aqueous medium. Rheological analysis of cryo-beads revealed its stability and increased stiffness after uranium adsorption. The maximum uranium adsorption (97\%) was observed at an initial $\mathrm{U}(\mathrm{vI})$ concentration of $100 \mathrm{mg} \mathrm{L}^{-1}$ at the $\mathrm{pH}$ range of 4.5-5.5 in DI water. The $0.1 \mathrm{M} \mathrm{HCl}$ solution was found to be an efficient eluent for the uranium desorption. This biosorbent showed $\sim 70 \%$ of uranium recovery after five repeated cycles for the uranium desorption. In addition, only $50 \%$ of $\mathrm{U}(\mathrm{vI})$ adsorption was observed in natural seawater after contact time of one day due to the weak cryogel-uranyl ion complexation in the presence of seawater components.

The synthesis of magnetic adsorbent $\left(\mathrm{AO}-\mathrm{Fe}_{3} \mathrm{O}_{4} / \mathrm{P}(\mathrm{GMA}-\mathrm{AA}-\right.$ MMA)) was performed by grafting amidoxime groups onto the surface of superparamagnetic polymer microspheres synthesized by a novel controlled radical polymerization technology using 1,1-diphenylethylene (DPE) as radical controlling agent. ${ }^{67}$ The prepared magnetic adsorbent was applied to adsorb uranium(vi) from aqueous solutions. An optimum U(vI) adsorption capacity of $200.5 \mathrm{mg} \mathrm{g}^{-1}$ was obtained at $\mathrm{pH} 4.5$ in DI water. The adsorption of $\mathrm{U}(\mathrm{vI})$ on the magnetic adsorbent was mainly attributed to surface complexation via the coordination of $\mathrm{U}(\mathrm{vI})$ ions with amidoxime groups. The adsorbent could also selectively adsorb $\mathrm{U}(\mathrm{vI})$ in aqueous solution containing co-existing ions efficiently. Moreover, the desorption studies showed (AO$\mathrm{Fe}_{3} \mathrm{O}_{4} / \mathrm{P}(\mathrm{GMA}-\mathrm{AA}-\mathrm{MMA})$ ) could be used repeatedly and adsorption capacity did not have any noticeable loss after five cycles.

In the recent times, magnetic adsorption based on molecular recognition in molecularly imprinted polymers (MIPs) has drawn considerable attention owing to high selectivity for target ion, excellent reusability as well as high stability. ${ }^{68}$ Based on this ion imprinted polymer (IIP) embedded with $\gamma$-methacryloxypropyltrimethoxysilane ( $\gamma$-MPS) coated magnetic particles were synthesized by bulk polymerization for selective extraction of uranyl. ${ }^{69}$ The U(VI) adsorption capacity of the magnetic polymers was found to be 1.1 and $0.95 \mathrm{mg} \mathrm{g}^{-1}$ for the IIP and its control ion non-imprinted polymer (NIP), respectively. The optimum time to reach equilibrium was $45 \mathrm{~min}$. Studies from binary mixtures of metal ions in aqueous solutions exhibited that the magnetic adsorbent selectivity followed the order: $\mathrm{U}(\mathrm{VI})$ $>\mathrm{Ni}$ (II) $>\mathrm{Pb}$ (II). In addition, the synthesized products were tested in the mine wastewater sampled from Germiston (South Africa) with a pH 2.6 , ORP $436 \mathrm{mV}$, and conductivity $680 \mu \mathrm{S} \mathrm{cm}^{-1}$. The mining site was previously engaged in open cast and deep mining activities in close vicinity of a water source. The sample contained $\mathrm{Au}$ (0.27 ppm), Co (22.95 ppm), Cr (0.83 ppm), Cu (11.25 ppm), Fe (1.8 ppm), Hg (0.67 ppm), Mn (72 ppm), Ni (48.3 $\mathrm{ppm}), \mathrm{U}$ (8.5 ppm), and $\mathrm{Zn}$ (54.75 ppm). Approximate $\mathrm{U}(\mathrm{vI})$ recoveries of $77 \%$ and $66 \%$ using the magnetic IIP and NIP, respectively, were recorded. The removal efficiency of magnetic IIP was higher than magnetic NIP due to the imprinting effect. Stability and reusability of the magnetic polymers were monitored up to the sixth cycle without significant loss in extraction ability.

Water soluble, polyacrylamide coated magnetite $\mathrm{Fe}_{3} \mathrm{O}_{4} @$ @PAM composites were prepared by in situ polymerization technique and tested as adsorbent to adsorb U(vI) ions from water by using batch adsorption technique. ${ }^{70}$ The adsorption isotherms were well fitted by the Langmuir adsorption model, and the maximum $\mathrm{U}(\mathrm{vI})$ adsorption capacity of $\mathrm{Fe}_{3} \mathrm{O}_{4} @ \mathrm{PAM}$ at $\mathrm{pH} 5.0 \mathrm{in}$ $0.01 \mathrm{M} \mathrm{NaCl}$ solution was around $221 \mathrm{mg} \mathrm{g}^{-1}$. Based on the Xray photoelectron spectroscopy (XPS) analysis, the nitrogencontaining functional groups on the surface of $\mathrm{Fe}_{3} \mathrm{O}_{4} @ P A M$ were involved in complex formation with $\mathrm{U}(\mathrm{vI})$. Acidic solution $(0.02 \mathrm{M} \mathrm{HCl})$ could be used to desorb the loaded $\mathrm{U}(\mathrm{vI})$ in $24 \mathrm{~h}$, and the adsorption ability of regenerated composite remained $>90 \%$ even after 5 cycles.

Magnetic glycidyl methacrylate resin particles with nanomagnetite core and glycidyl methacrylate $/ N, N^{\prime}$-methylene-bisacrylamide (GMA/MBA) resin shell were prepared and immobilized with ethylenediamine and diethylenetriamine for removal of $\mathrm{U}(\mathrm{vI})$ in water samples. ${ }^{71}$ The maximum $\mathrm{U}(\mathrm{vI})$ adsorption capacities on R-1 and R-2 were recorded to be 92 and $158 \mathrm{mg} \mathrm{g}^{-1}$, respectively, at pH 5 in DI water. The kinetic results revealed that the pseudo-second-order adsorption was the predominant mechanism. Hexavalent uranium removal efficiency for both resins increased as temperature increased showing the endothermic nature of the adsorption process. Among the various applied isotherm models including Langmuir, Freundlich, Temkin, and Dubinin-Radushkevich, the adsorption reaction was best correlated with Langmuir model. To have real application of these synthesized resins, uranium was extracted successfully from three granite samples collected (from Gabal Gattar pluton, North Eastern Desert, Egypt) after the wet acidic digestion of granite samples. The studied resins showed good durability and regeneration using $\mathrm{HNO}_{3}$. 
3.1.2.2 Non-polymeric coating. Surfactants form selfaggregates by the immobilization or by the physical adsorption at the surface of magnetic core and protect it from oxidation by creating a shell structure around it. In this context, the anionic surfactant sodium dodecyl sulfate (SDS) coated $\mathrm{Fe}_{3} \mathrm{O}_{4}$ particles were synthesized and further functionalized with organosiloxanes (labeled as $\mathrm{Fe}_{3} \mathrm{O}_{4}$ @APTMS). ${ }^{72}$ The as prepared adsorbent showed high adsorption affinity of $151.80 \mathrm{mg}^{-1}$ at $\mathrm{pH}$ 6 towards $\mathrm{U}(\mathrm{vI})$ which was expected due to complexation reaction between surface amino groups and $\mathrm{U}(\mathrm{vI})$. The results revealed that the presence of interfering ions such as $\mathrm{Na}^{+}, \mathrm{K}^{+}$, $\mathrm{Ca}^{2+}, \mathrm{Sr}^{2+}$, and $\mathrm{Mg}^{2+}$ had no significant effect on adsorption of $\mathrm{U}(\mathrm{vI})$ on $\mathrm{Fe}_{3} \mathrm{O}_{4} @ A P T M S$. The adsorbent was readily regenerated by $0.1 \mathrm{M} \mathrm{NaOH}$ and reused for three times.

Surfactant-coated ferroferric oxide immobilized with oxine functionality was prepared and used as magnetic adsorbent for $\mathrm{U}(\mathrm{vI}) .^{73}$ The $\mathrm{U}(\mathrm{vI})$ adsorption was strongly dependent on $\mathrm{pH}$ and independent of ionic strength, signifying that the adsorption was due to an inner-sphere surface complexation. The $0.2 \mathrm{~mol} \mathrm{~L}^{-1} \mathrm{HCl}$ solution was used as a desorbing solution for the regeneration experiments, and the reusability of the magnetic oxine was decreased from $82 \%$ to $78 \%$ in three adsorption-desorption cycles.

The $\mathrm{Fe}_{3} \mathrm{O}_{4} @ \mathrm{CD}$ MCs were synthesized by using a simple chemical co-precipitation method for the removal of $\mathrm{Eu}(\mathrm{III})$ from aqueous phase. ${ }^{74}$ In comparison to $\mathrm{Fe}_{3} \mathrm{O}_{4}$, the prepared $\mathrm{Fe}_{3} \mathrm{O}_{4} @ \mathrm{CD} \mathrm{MCs}$ demonstrated a higher adsorption capacity toward $\mathrm{Eu}(\mathrm{III})$. The adsorption kinetics of $\mathrm{Eu}(\mathrm{III})$ on $\mathrm{Fe}_{3} \mathrm{O}_{4} @ \mathrm{CD}$ MCs could attain equilibrium within $3 \mathrm{~h}$. The $\mathrm{pH}$-dependent and ionic strength-independent $\mathrm{Eu}(\mathrm{III})$ adsorption on the surface of $\mathrm{Fe}_{3} \mathrm{O}_{4} @ \mathrm{CD} \mathrm{MCs}$ suggested that the adsorption mechanism of $\mathrm{Eu}(\mathrm{III})$ was inner-sphere surface complexation at low $\mathrm{pH}$, whereas the removal of $\mathrm{Eu}(\mathrm{III})$ was achieved by simultaneous precipitation and inner-sphere surface complexation at $\mathrm{pH}>6.8$. The Langmuir and Freundlich models were employed to simulate adsorption isotherms for $\mathrm{Eu}(\mathrm{III})$ on $\mathrm{Fe}_{3} \mathrm{O}_{4} @ \mathrm{CD}$ MCs. Although the adsorbent had low cost with high removal efficiency, it did not regenerate, which may limit its real application potential.

Furthermore, the bio-nanocomposite with uniform decoration of m-NPs on a fungus surface was synthesized by a selfassembly technique. This bio-nanocomposite was then used to adsorb radionuclides such as $\mathrm{Sr}(\mathrm{II}), \mathrm{Th}(\mathrm{IV})$ and $\mathrm{U}(\mathrm{VI})$ in water. ${ }^{75}$ These m-NPs were bound to fungus surface by means of chemical bonds as evidenced by Fourier transform infrared spectroscopy (FTIR). According to the Langmuir isotherm model maximum adsorption capacities of fungus- $\mathrm{Fe}_{3} \mathrm{O}_{4}$ were 100.9, 223.9 and $280.8 \mathrm{mg} \mathrm{g}^{-1}$ for $\mathrm{Sr}$ (II) and $\mathrm{U}(\mathrm{VI})$ at $\mathrm{pH} \mathrm{5.0,} \mathrm{and}$ Th(Iv) at pH 3.0, in $0.01 \mathrm{M} \mathrm{NaClO}_{4}$ solution respectively, around $303 \mathrm{~K}$. XPS analysis predicted the formation of inner-sphere radionuclide complexes due to bonding with oxygen-bearing functionalities (i.e., alcohol, acetal and carboxyl) of fungus$\mathrm{Fe}_{3} \mathrm{O}_{4}$. The thermodynamic parameters confirmed that the adsorption of radionuclides on fungus- $\mathrm{Fe}_{3} \mathrm{O}_{4}$ was a spontaneous and endothermic process. Moreover, it was noticed that fungus- $\mathrm{Fe}_{3} \mathrm{O}_{4}$ could be regenerated with $0.1 \mathrm{M} \mathrm{HCl}$ desorbing solution and reused at least five times.
Another interesting study involves the use of organophosphorus solvent, Di-(2-ethylhexyl) phosphoric acid (D2EHPA), coated onto magnetic nanoparticles by simple mixing and drying and the resulting surface-coated adsorbent was used for removal of $\mathrm{U}(\mathrm{vI})$ from the raffinate solution of Isfahan's Uranium conversion plant. ${ }^{76}$ The solution contained diverse cations (U (23 ppm), Na (4360 ppm), Al (0.32 ppm), Ni (2 ppm), Bi (0.2 ppm), Nb (0.1 ppm), Ca (0.1 ppm)) and anions $\left(\mathrm{F}^{-}\right.$ (18 $755 \mathrm{ppm}), \mathrm{NO}_{3}{ }^{-}$(4870 $\left.\mathrm{ppm}\right), \mathrm{SO}_{4}{ }^{2-}$ (1648 ppm), $\mathrm{Cl}^{-}$(210 $\mathrm{ppm})$ ). After the adsorption of uranium, the final concentration of $\mathrm{U}(\mathrm{vI})$ was lowered to $0.7 \mathrm{ppm}$ in the waste such that it could be safely disposed in accordance to EPA and Nuclear Regularity Commission (NRC) rules. The optimum uranium recovery was obtained when $25 \% \mathrm{w} / \mathrm{w}$ D2EHPA/m-NPs were used in $0.5 \mathrm{M}$ $\mathrm{HNO}_{3}$ solution.

Humic acids, the major organic constituents of soil are produced by biodegradation of dead organic matter. It is a complex mixture of many different acids containing carboxyl and phenolate groups. Humic acids can form stable complexes with ions that are frequently found in the natural environment creating humic colloids. In view of this point, environmentalists synthesized humic acid-coated $\mathrm{Fe}_{3} \mathrm{O}_{4}$ magnetic nanoparticles ( $\mathrm{Fe}_{3} \mathrm{O}_{4} @ \mathrm{HA} \mathrm{MNPs}$ ) as an adsorbent to evaluate its removal efficiency towards $\mathrm{Eu}(\mathrm{III})$ under various environmental conditions. ${ }^{77}$ The kinetic studies showed that Eu(III) adsorption onto $\mathrm{Fe}_{3} \mathrm{O}_{4} @ \mathrm{HA}$ MNPs could attain equilibrium within $30 \mathrm{~min}$ and 99\% Eu(II) adsorption was observed at $\mathrm{pH} 8.5$ with an initial $\mathrm{Eu}(\mathrm{III})$ concentration of $3 \mathrm{mg} \mathrm{L}^{-1}$ in different solutions including $0.05 \mathrm{M} \mathrm{NaNO}_{3}, 0.05 \mathrm{M} \mathrm{NaCl}, 0.05 \mathrm{M} \mathrm{Na}_{2} \mathrm{SO}_{4}$, and $0.05 \mathrm{M} \mathrm{Na}_{2} \mathrm{HPO}_{4}$. The rapid kinetics and high removal efficiency was positively correlated with the abundant surface sites provided by the coated HA macromolecules. The removal of $\mathrm{Eu}(\mathrm{III})$ was dominated by inner-sphere surface complexation. The synthesized adsorbent showed good recycling performance up to six cycles using $0.01 \mathrm{M} \mathrm{HCl}$ solution as an eluent. Based on the negligible leachability of Eu from the loaded adsorbent in tap water over a period of three months, the $\mathrm{Fe}_{3} \mathrm{O}_{4} @ \mathrm{HA}$ MNPs was proposed as a highly effective material for the enrichment and pre-concentration of radionuclide Eu(III) or other trivalent lanthanides/actinides in geological repositories or in nuclear waste management.

\subsection{Substrates of magnetite-based adsorbents}

3.2.1 Carbonaceous substrates. Owing to high specific surface areas, chemical inertness, biocompatibility and thermal stability, carbonaceous substrates have gained enormous attention in environmental remediation. In addition, carbonaceous substrate provides stable sites for magnetite nanoparticles loading to prevent their oxidation and aggregation. Various kinds of magnetic composites containing porous carbon such as activated carbon, multi-walled carbon nano tubes, mesoporous carbons, and graphene oxide have been synthesized to remove radioactive contaminants from aqueous solutions. Among these composites, graphene oxide (GO) based magnetite composites have received the most research interest owing to their outstanding physicochemical properties of GO. ${ }^{78}$ 
In 2013, the chemical co-precipitation strategy was adopted to synthesize magnetic graphene/iron oxides composite $\left(\mathrm{Fe}_{3} \mathrm{O}_{4}\right)$ $\mathrm{GO})$ for the pre-concentration and solidification of $\mathrm{U}(\mathrm{vI})$ ions from aqueous solutions. ${ }^{79}$ The $\mathrm{U}(\mathrm{vI})$ adsorption on $\mathrm{Fe}_{3} \mathrm{O}_{4} / \mathrm{GO}$ was strongly influenced by $\mathrm{pH}$ and was insensitive to ionic strength variation. The maximum $\mathrm{U}(\mathrm{vI})$ adsorption capacity was $69.49 \mathrm{mg} \mathrm{g}^{-1}$ at $\mathrm{pH} 5.5$ in $0.01 \mathrm{M} \mathrm{KNO}_{3}$ solution and the adsorption was favored at elevated temperatures. Although the composite could be reused for six cycles, it was unstable due to considerable leaching of iron below pH 8 which is undesirable.

By integrating the multiple benefits of GO and magnetic $\mathrm{PB}$ nanoparticles, $\mathrm{PB} / \mathrm{Fe}_{3} \mathrm{O}_{4} / \mathrm{GO}$ nanocomposite was prepared for the removal of radioactive cesium in water.$^{80}$ Around $70 \%$ of Cs was adsorbed onto $\mathrm{PB} / \mathrm{Fe}_{3} \mathrm{O}_{4} / \mathrm{GO}$ within $30 \mathrm{~min}$ and the maximum Cs uptake capacity was $55.56 \mathrm{mg} \mathrm{g}^{-1}$ in DI water. The enhanced adsorption efficiency and capacity was due to the anchoring technology, which reduced the aggregation of nanoparticles and increased the effective adsorption surface of the adsorbent. The composite was capable of removing Cs from real environmental samples and stable, but not readily regenerated.

Owing to high reactivity of amidoxime towards uranyl, amidoximated magnetite/graphene oxide (AOMGO) composite was prepared in two steps. ${ }^{\mathbf{8 1}}$ The first step involved the simple coprecipitation of magnetic graphene oxide and the second step involved amidation of GO with diaminomaleonitrile followed by the treatment with hydroxylamine hydrochloride to obtain the final products. The resulting AOMGO composite showed maximum U(vI) adsorption capacity of $284.9 \mathrm{mg} \mathrm{g}^{-1}$ at $\mathrm{pH} 5$ in $0.01 \mathrm{M} \mathrm{NaClO}_{4}$ solution which is relatively high due to formation of stable complexes between amidoxime and other oxygencontaining functional groups on the surfaces of AOMGO with $\mathrm{U}(\mathrm{vI})$.

Lately, $\mathrm{CB}[6] / \mathrm{GO} / \mathrm{Fe}_{3} \mathrm{O}_{4}$ was fabricated by linking the $\mathrm{CB}[6]$ via hydrogen bonding and introducing numerous well dispersed $\mathrm{Fe}_{3} \mathrm{O}_{4}$ nanoparticles by co-precipitation approach. ${ }^{\mathbf{8 2}}$ The resultant composite was investigated for $\mathrm{U}(\mathrm{vI})$ removal and manifested the competitive adsorption performance and acceptable reusability. In addition, the composite could be regenerated by acidic solution in a contact time of $24 \mathrm{~h}$, with only minute iron leaching.

3.2.2 Inorganic clay. Clay minerals have a distinct layered morphology composed of the octahedral $\left(\mathrm{Al}^{3+}, \mathrm{Fe}^{2+}, \mathrm{Fe}^{3+}\right.$, or $\left.\mathrm{Mg}^{2+}\right)$ and tetrahedral $\left(\mathrm{Si}^{4+}\right)$ structures depending on the type of clay. ${ }^{83}$ Owing to isomorphic substitution, the clay minerals have surface charge which play an important role to capture metal ions. The use of clay minerals as substrate materials prevents the particle aggregation, enhances the dispersion as well as improves stability. Common clay minerals include kaolinite, bentonite, montmorillonite, layered double hydroxide, zeolite, attapulgite, sepiolite, halloysite, etc. At present, many kinds of clay minerals have been employed to prepare magnetic composites to adsorb contaminants from water. ${ }^{84}$

To investigate the adsorption behavior of $\mathrm{U}(\mathrm{vI})$ from aqueous solutions, $\beta$-cyclodextrin ( $\beta$-CD) was chemically grafted onto halloysite nanotube/iron oxides and applied in batch system as a function of various environmental parameters. ${ }^{85}$ The maximum removal ( $\sim 92 \%)$ of initial $4.75 \mathrm{mg} \mathrm{L}^{-1}$ uranium was observed at $\mathrm{pH} 7$ in $0.01 \mathrm{M} \mathrm{NaNO}_{3}$ solution. The pseudo-secondorder model was found to be best correlated model with kinetic data, confirming that chemisorption was the rate-controlling mechanism. The removal efficacy of $\mathrm{U}(\mathrm{vI})$ on $\mathrm{CD} / \mathrm{HNT} / \mathrm{iron}$ oxide was higher than that on bare HNTs and HNT/iron oxides. This enhancement was caused by the multiple $\mathrm{OH}$ groups provided by surface-grafted $\beta$-CD. Satisfactory treatment efficiency was observed by $\mathrm{CD} / \mathrm{HNT} /$ iron oxide in simulated wastewater. In addition, the $\mathrm{CD} / \mathrm{HNT} /$ iron oxide was proposed as a backfilling material for a deep geological disposal of highlevel radioactive waste.

The co-precipitation approach was adopted to synthesize attapulgite-iron oxide magnetic composites for the efficient preconcentration of $\mathrm{Eu}(\mathrm{III})$ from aqueous solution. ${ }^{86}$ The resultant $\mathrm{Eu}(\mathrm{III})$ adsorption isotherms were well simulated by Langmuir model with and the maximum adsorption capacity of $117 \mathrm{mg}$ $\mathrm{g}^{-1}$ at $\mathrm{pH} 5.0$ in $0.01 \mathrm{M} \mathrm{NaClO}_{4}$ solution. The adsorption behavior was improved in the presence of humic acids and the observed enhancement in Eu(III) adsorption at low $\mathrm{pH}$ was due to strong complexation of Eu(III) with surface adsorbed humic acid on solid particles, whereas the reduction in adsorption at high $\mathrm{pH}$ was due to the formation of soluble Eu-HA complexes.

Very recently, Yang et al. ${ }^{89}$ reported the synthesis of chitosan grafted magnetic bentonite using a plasma induced grafting method and investigated its potential usage as an adsorbent for radioactive cesium in simulated groundwater and seawater (sampled from Pacific Ocean near Hamamatsu, Japan). The results showed enhanced coagulation due to plasma modification. In addition, this material exhibited good magnetic sensitivity as well as low turbidity and high stability in the seawater sample. Multifunctional adsorbent with superparamagnetic and PB particles was synthesized in the presence of sepiolite silicate (as porous platform) by one pot method. ${ }^{87}$ The efficacy of the resulting nanostructure was determined for the adsorption of Cs ions from aqueous media. The maximum Cs removal capacity was $102 \mathrm{mg} \mathrm{g}^{-1}$ at $22{ }^{\circ} \mathrm{C}$ in DI water. The thermodynamic studies suggested that Cs adsorption onto Sep/NPPB was

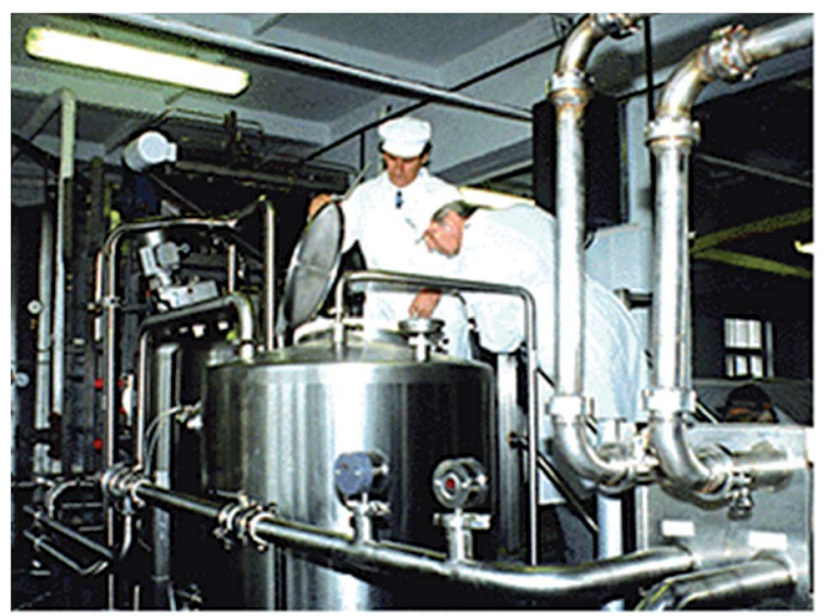

Fig. 5 The MAG*SEPSM milk decontamination system at Ovruch, Ukraine 1997 . $^{1}$ 
a typical physio-sorption process due to free energy around $-14.5 \mathrm{~kJ} \mathrm{~mol}^{-1}$.

Surface modification of a magnetic $\mathrm{Mg}-\mathrm{Al}$ layered double hydroxide with citrate acid $\left(\mathrm{C}_{6} \mathrm{H}_{5} \mathrm{O}_{7}{ }^{3-}\right)$ by ion exchange was carried out for the efficient removal of $\mathrm{U}(\mathrm{vI})$ that involved formation of the citrate-uranium complexes in the interlayer of the magnetic citrate $\mathrm{Mg}-\mathrm{Al}$ layered double hydroxide. ${ }^{88}$ The adsorption process was in good agreement with Freundlich

(a)
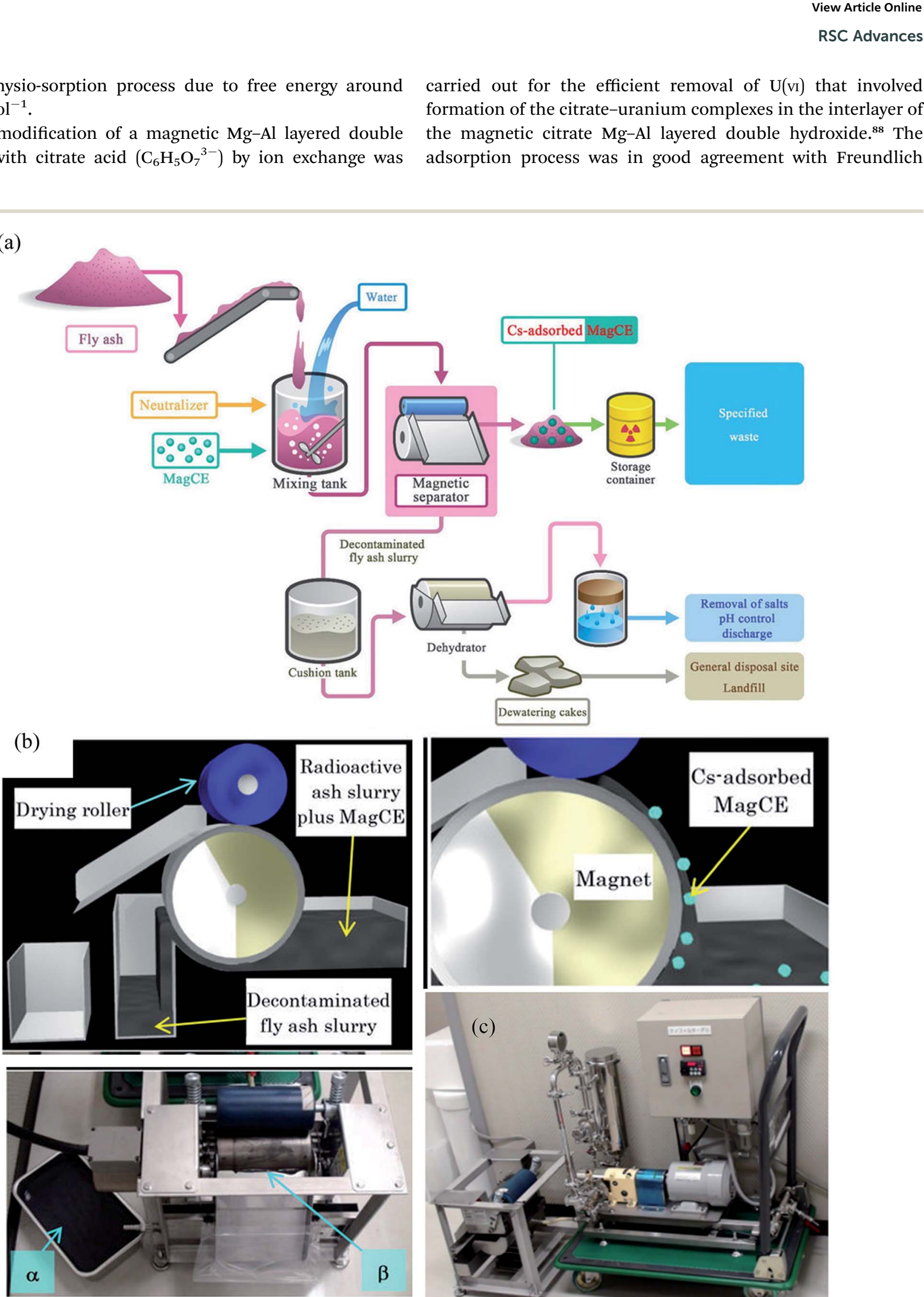

(c)

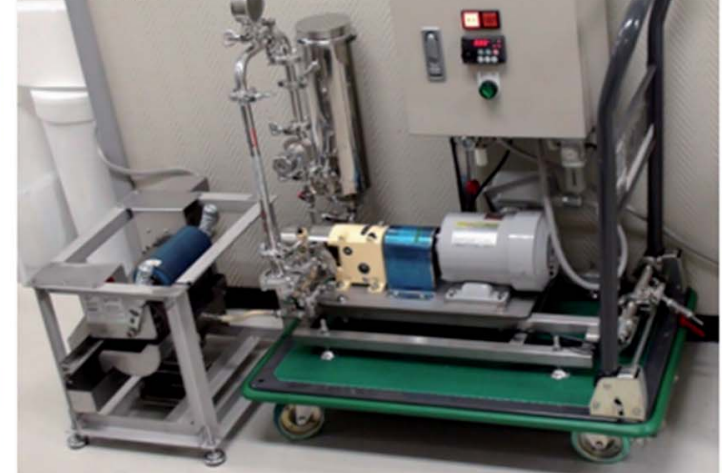

Radioactive cesium-eliminated fly ash slurry $(\alpha$ and the cesium-adsorbed MagCE $(\beta)$

Fig. 6 (a) Schematic representation of the concept of the compact decontamination system composed of a slurry mixing tank, a magnetic separator to recover the MagCE and the dewatering equipment. (b) Schematic representation of the decontamination involving removal of radioactive cesium using MagCE and a drum-type magnetic separator (c) pilot scale decontamination system. ${ }^{91}$ 
model and pseudo-second-order kinetics. The results demonstrated that the maximum adsorption capacity of $180 \mathrm{mg} \mathrm{g}^{-1}$ with the initial $\mathrm{U}(\mathrm{vI})$ concentration was $200 \mathrm{mg} \mathrm{L}^{-1}$ at $298 \mathrm{~K}$ in DI water.

\section{Case studies}

Although numerous studies have been conducted for the effective removal of radionuclides by magnetite-based adsorbents as presented in Tables 2 and 3. However, these studies present laboratory scale treatment. Therefore, the available information of pilot scale setup is still very scarce due to limited commercialization of operational setup and lack of regulatory framework for the use of magnetite adsorbents in water remediation. The representative case studies of magnetite-based adsorbents are summarized here to provide basic knowledge for applications to the real world environmental problems and to suggest the best option for their successful performance.

\subsection{MAG*SEPSM technology for the decontamination of radioactive milk}

After the Chernobyl nuclear accident various radionuclides were expelled into the environment, including ${ }^{137} \mathrm{Cs}$ which contaminated the grazing land for the cattle in the Ukraine. Consequently, milk products were contaminated and Cs levels were exceeding the international drinking standard of $370 \mathrm{~Bq} /$ L. $^{90}$ To remove the radioactive cesium from milk, the $\mathrm{MAG}^{*} \mathrm{SEP}^{\mathrm{SM}}$ treatment system was installed at the Ovruch Dairy in Ukraine (Fig. 5). It is a separation technology that uses magnetic particles to selectively adsorb contaminants such as heavy metals, radionuclides, or nitrates from contaminated water or other liquids. The vendor claimed that this technology could also treat the soil and could be operated in situ or ex situ to treat large volumes of liquids.

The MAG*SEP ${ }^{\mathrm{SM}}$ particles have a magnetic core embedded in a polymer-based protective covering, and outer covering composed of a specific functional group. The demonstration tests were conducted at Argonne National Laboratory which revealed that the process could remove $95 \%$ of radioactive cesium from liquid milk. These particles had high adsorption capacity and good recyclability. However, these particles had a lack of selectivity and poor capturing ability when metals are present in various oxidation states. Low $\mathrm{pH}$ solutions significantly reduced the adsorption performance. In addition, the recycled $\mathrm{MAG}^{*} \mathrm{SEP}^{\mathrm{SM}}$ particles contained the traces of contaminants that could not be used for different applications due to probable cause of cross contamination.

\subsection{Large scale study using a drum magnetic type separator to decontaminate cesium eluted ash slurry}

Around 140000 tons of fly ash was generated by the Fukushima nuclear accident. This fly ash was concentrated with watersoluble radioactive cesium that could pose severe health issues by contaminating the groundwater. Conventional methods to remove Cs required a series of complicated steps including the separation of cesium eluted water from fly ash slurry, addition of flocculants and use of a decontaminant powder to bind cesium. However, the rapid separation of such a finely divided powder is problematic. In addition, cesium in dewatered fly ash cakes has a significant potential to leach and therefore, contaminating the natural resources. To decontaminate radioactive cesium, magnetically guidable cesium eliminator (MagCE) adsorbents were synthesized which have porous structure, ferromagnetic material, and alkaline-resistant nickel ferrocyanide. ${ }^{91}$ The direct addition of MagCE to the fly ash slurry and rapid magnetic separation reduced the number of steps for decontamination and could avoid cesium leaching from dewatered cakes. The large-scale (Fig. 6) demonstration experiments with fly ash $(1 \mathrm{~kg})$ in water $(10 \mathrm{~L})$ revealed $>99 \%$ Cs removal from liquid component by $\mathrm{MagCE}$ using a drum type magnetic separator. The author proposed the use of MagCE for large scale removal of water soluble cesium and other radionuclides from soil and plant biomass.

\section{Summary and recommendations}

Traditional treatment technologies (coagulation, precipitation, ion exchange etc.) are energy-intensive and produce significant amounts of radioactive sludge. The use of nano-adsorbents in the decontamination of radioactive water is gaining interest by leaps and bounds. Especially the carbon based superparamagnetic composite adsorbents reduced solid waste production owing to their high removal capacities contributed by several factors (including exceptionally high surface area, magnetic susceptibility, and high chemical stability). In addition, the affectivity and selectivity of these adsorbents can be easily tuned by surface modification to capture low levels of radionuclides in bulk water. In contrast to conventional methods, less energy is required for the collection of magnetic particles by means of an external magnet.

So far, the behavior of magnetite-based adsorbents under irradiation has not been investigated therefore future research should be done to explore the radiations induced effect on magnetic adsorbents.

From the industrial point of view, it's necessary to focus on the simple, convenient and low-cost preparation methods avoiding harsh conditions. The precursors used for the synthesis and surface modification of the magnetic adsorbents should be ecologically benign. In addition, organic functionality should follow the CHON principle, i.e. (preferably composed of the elements $\mathrm{C}, \mathrm{H}, \mathrm{O}$, and N), which implies that at the end of their useful life, they can be completely incinerated to minimize the generation of secondary waste. Ideally, the adsorbent should be chemically and radiolytically stable so that it can withstand the optimized conditions for several consecutive adsorptions and desorption cycles without leaching of the magnetic core, coating, and functional groups. High preconcentration factor (which is the ratio of the solution volume before adsorption to the eluent volume during the desorption process) is desired to concentrate the recovered radionuclides from the bulk solution, so that recovered radionuclide could be safely disposed in a small volume. However, this factor has been overlooked and not discussed in details yet. Similarly, the 
distribution coefficient (which is important at dilute radionuclide concentrations) was not evaluated in detail in the reviewed literatures. Therefore, for practical perspectives, both these factors need to be considered for the future studies.

For large scale application of adsorbents short equilibration time is preferred for both adsorption and desorption processes to minimize the operation costs. Even though, the majority of documented studies focused on the small adsorption equilibrium time, desorption time was long (and/or not studied in detail) which might affect the economic feasibility of the process. Selectivity is a key parameter for any adsorbent because the presence of the common alkali and alkaline earth metal ions in most environmental water compete for the same binding sites, resulting in poor removal performance of the adsorbent towards the target radionuclide. The majority of the listed magnetic adsorbents do not exhibit high selectivity except for those incorporating certain functional groups i.e. Prussian blue, amido oxime, phosphonates etc.

The large number of reviewed adsorption studies were carried out in laboratory environments with controlled media and aqueous samples, not considering the complex environmental conditions of real contaminated sites. It is noteworthy to mention here that majority of these studies incorporate very high initial concentration of radionuclides which is not environmentally realistic.

The recent studies described the batch adsorption process in detail, which is a first stage to examine the efficacy of any adsorbent to remove radionuclides; nevertheless, it is not considered as a convenient approach for large scale water treatment. This issue could be compensated by the flowthrough column based operation that could be used directly at a continuous water supply. However, many magnetic adsorbents have a powdered-like appearance, which could cause plugging issues and thus reduce flow rates and/or clog the filter pores. Fortunately, the synthesis of new porous magnetic composites seems to be a promising strategy to respond to the above mentioned technical problem. Moreover, its common practice to add organic binding agents as an additive in powdered adsorbent to make structured adsorbents (beads, granules or pellets) and to impart mechanical stability needed to withstand the stress during operation. However, the performance of the structured adsorbents was reduced due to pore blockage by the binder. In addition, there is possibility of leaching of binder which will in turn increase the Total Organic Carbon (TOC) of the treated water. Therefore, binder-free processing approaches such as pulsed current processing and/or 3D printing should be investigated for the bulk production of structured adsorbents.

Although, magnetite-based adsorbents have great advantages in comparison to conventional adsorbents but still their use is limited to labs scale water treatment due to their high production cost and the complex equipment required for the separation.

The continuous decline in adsorption performance was experienced from the recent pilot scale study due to the instability of magnetic adsorbent and unwanted accumulation of magnetic particles in the pipes and peripheral components

resulting in the reduced flow rate. ${ }^{143}$ In addition, to separate the magnetic adsorbent, magnetic drum separator (MDS) and high gradient magnetic separator (HGMS) were used but MDS was unable to separate magnetic adsorbent completely while HGMS required regular flushing resulting in discontinuous operation and the dilution of the final particle concentrate. To avoid, aforementioned issues for the large-scale removal of radionuclides, it is suggested that one should use stable magnetic adsorbents and high-gradient filters (HGF) or a superconducting magnetic separation (SMS) system as a substitute to electromagnets. Finally, the cost of adsorbents should be carefully evaluated for their preparation and the regeneration for the long term industrial use.

Once these issues are properly addressed, these modified adsorbents with improved characteristics could be effectively utilized in closed system without clogging the filter pores, while in open environment these could be easily recovered and reused. Especially in the reactor decommissioning and/or nuclear accident situations, because robots could spread these adsorbents in high radiation fields and retrieve the captured radionuclides with help of high density electromagnet.

\section{Abbreviation}

\begin{tabular}{|c|c|}
\hline$\gamma$-MPS & $\gamma$-Methacryloxypropyltrimethoxysilane \\
\hline AAM & Alginate agarose magnetite \\
\hline $\mathrm{AC}$ & Activated carbon \\
\hline $\mathrm{AO}$ & Amidoxime \\
\hline $\begin{array}{l}\text { AO/AMPS- } \\
\text { MBA }\end{array}$ & $\begin{array}{l}\text { Acrylamidoxime- } c o-2 \text {-acrylamido-2- } \\
\text { methylpropane sulfonic acid crosslinked with } \\
N, N \text {-methylenebisacrylamide }\end{array}$ \\
\hline APS & Aminopropylsilane \\
\hline $\begin{array}{l}\text { APTMS } \\
\text { (APMS) }\end{array}$ & 3-Aminopropyl trimethoxysilane \\
\hline $\mathrm{BP}$ & Tetraethyl-3-aminopropane-1,1-bisphosphonate \\
\hline BMSPN & $\begin{array}{l}N, N^{\prime} \text {-Bis(3-methoxylsalicylidene)-1,2- } \\
\text { phenylenediamine }\end{array}$ \\
\hline $\mathrm{CB}[6]$ & Cucurbit[6]uril \\
\hline CB-MNs & Calixarene-based magnetic nanoparticles \\
\hline CMK-3 & Mesoporous carbon \\
\hline CMLH & $\begin{array}{l}\text { Calcined magnetic layered double hydroxide/ } \\
\text { hydroxyapatite }\end{array}$ \\
\hline CNTs & Carbon nanotubes \\
\hline D2EHPA & Di-(2-ethylhexyl) phosphoric acid \\
\hline DA & Dopamine \\
\hline DPAO & $\begin{array}{l}\text { Diacrylamidoxime } \\
\text { triaethylenetetralevopimaramide }\end{array}$ \\
\hline DPTS & Diethylphosphatoethyltriethoxysilane \\
\hline $\mathrm{D} t \mathrm{BuCH} 18 \mathrm{C} 6$ & Di-tert-butyl cyclohexano-18-crown-6 \\
\hline DTC & Dithiocarbamate \\
\hline EDA-MCCS & $\begin{array}{l}\text { Ethylene diamine magnetic carboxymethyl } \\
\text { chitosan nanoparticles }\end{array}$ \\
\hline EMMC & Ethylenediamine-modified magnetic chitosan \\
\hline GMA/BPA & $\begin{array}{l}\text { Glycidyl methacrylate } / N, N^{\prime}- \\
\text { methylenebisacrylamide }\end{array}$ \\
\hline GO & Graphene oxide \\
\hline
\end{tabular}

$\gamma$-MPS

AAM

$\mathrm{AC}$

AO/AMPS-

APS

APTMS

(APMS)

$\mathrm{BP}$

$\mathrm{CB}[6]$

CB-MNs

CMK-3

$\mathrm{CMLH}$

CNTs

D2EHPA

$\mathrm{DA}$
$\gamma$-Methacryloxypropyltrimethoxysilane

Activated carbon

methylpropane sulfonic acid crosslinked with $\mathrm{N}, \mathrm{N}$-methylenebisacrylamide

Aminopropylsilane

Tetraethyl-3-aminopropane-1,1-bisphosphonate phenylenediamine

Calixarene-based magnetic nanoparticles

hydroxyapatite

Di-(2-ethylhexyl) phosphoric acid

Diacrylamidoxime

triaethylenetetralevopimaramide

Dithiocarbamate

chitosan nanoparticles

Glycidyl methacrylate $/ N, N^{\prime}$

Graphene oxide 


$\begin{array}{ll}\text { HA } & \text { Humic acid } \\ \text { HCC } & \text { Hydrothermal cross-linking chitosan } \\ \text { HNT } & \text { Halloysite nanotube } \\ \text { IIP } & \text { Ion imprinted polymer } \\ \text { IMCR } & \text { Ion-imprinted magnetic chitosan resins } \\ \text { KTiFC } & \text { Potassium titanium ferrocyanide } \\ \text { LDH } & \text { Layered double hydroxide } \\ \text { MMSNs-PP } & \text { Magnetic mesoporous silica nanoparticles- } \\ & \text { phosphonate } \\ \text { MMT } & \text { Montmorillonite } \\ \text { MNC } & \text { Magnetic nanocluster } \\ \text { MS } & \text { Magnesium silicate } \\ \text { MZC } & \text { Magnetic zeolite composite } \\ \text { PAM } & \text { Polyacrylamide } \\ \text { PA-SMM } & \text { Phosphonic acid-functionalized silica magnetic } \\ & \text { adsorbent } \\ \text { PB } & \text { Prussian blue } \\ \text { P(GMA-AA- } & \text { Poly glycidyl methacrylate acrylic acid methyl } \\ \text { MMA) } & \text { methacrylate } \\ \text { PAMAMG3 } & \text { Third generation poly(amido) amine } \\ \text { PVA } & \text { Polyvinyl alcohol } \\ \text { SDS } & \text { Sodium dodecyl sulfate } \\ \text { TETA-MCS } & \text { Triethylene-tetramine modified magnetic } \\ \text { TMS } & \text { chitosan adsorbents } \\ & \text { N-[(3-Trimethoxysilyl)propyl]ethylenediamine } \\ \text { triaceticacid trisodium }\end{array}$

\section{Conflicts of interest}

There are no conflicts to declare.

\section{Acknowledgements}

This work was supported by "The GAIA Project" by the Korea Ministry of Environment [RE201402059]. This research was also supported by the National Research Foundation of Korea (NRF) grant funded by the Korean government (MSIP: Ministry of Science, ICT and Future Planning) (No. NRF-2016R1D1A1B02013310).

\section{Notes and references}

1 MAG*SEPSM technology will decontaminate radioactive milk, http://infohouse.p2ric.org/ref/14/0_initiatives/init/ oct97/robot.htm, accessed 5/24/2017.

2 Q.-H. Hu, J.-Q. Weng and J.-S. Wang, J. Environ. Radioact., 2010, 101, 426-437.

3 J. Duruibe, M. Ogwuegbu and J. Egwurugwu, Int. J. Phys. Sci., 2007, 2, 112-118.

4 M. Arias-Estévez, E. López-Periago, E. Martínez-Carballo, J. Simal-Gándara, J.-C. Mejuto and L. García-Río, Agric., Ecosyst. Environ., 2008, 123, 247-260.

5 D. A. Atwood, Radionuclides in the Environment, John Wiley \& Sons, 2013.

6 USEPA, In situ treatment technologies for contaminated soil, United States Environmental Protection Agency Solid Waste and Emergency Response, 2006.
7 M. Gavrilescu, L. V. Pavel and I. Cretescu, J. Hazard. Mater., 2009, 163, 475-510.

8 P. Cazzola, A. Cena, S. Ghignone, M. C. Abete and S. Andruetto, Environ. Health, 2004, 3, 1.

9 L. Kosarek, Environ. Sci. Technol., 1979, 13, 522-525.

10 G. R. Najem and L. K. Voyce, Am. J. Public Health, 1990, 80, 478-480.

11 R. Clay, Environ. Health Perspect., 2001, 109, A162.

12 K. L. Mossman, Environ. Health Perspect., 2003, 111, 13.

13 USEPA, U.S. Environmental Protection Agency, Washington DC, 2000, vol. 65, pp. 76708-76753.

14 I. Katsoyiannis and A. Zouboulis, Desalin. Water Treat., 2013, 51, 2915-2925.

15 B. J. Lesikar, R. Melton, M. Hare, J. Hopkins and M. Dozier, Drinking Water Problems: Radionuclides, 2006, p. B-6192.

16 Handling and Processing of Radioactive Waste from Nuclear Applications, Technical reports series No. 402, IAEA, 2001.

17 USEPA, Potential Nano-Enabled Environmental Applications for Radionuclides Washington, DC 20460 EPA 402-R-09002, 2009.

18 S. Yamamoto, S. Sugiyama, O. Matsuoka, K. Kohmura, T. Honda, Y. Banno and H. Nozoye, J. Phys. Chem., 1996, 100, 18474-18482.

19 D. Mehta, S. Mazumdar and S. K. Singh, Journal of Water Process Engineering, 2015, 7, 244-265.

20 S. C. Tang and I. M. Lo, Water Res., 2013, 47, 2613-2632.

21 R. Kaur, A. Hasan, N. Iqbal, S. Alam, M. K. Saini and S. K. Raza, J. Sep. Sci., 2014, 37, 1805-1825.

22 P. Xu, G. M. Zeng, D. L. Huang, C. L. Feng, S. Hu, M. H. Zhao, C. Lai, Z. Wei, C. Huang and G. X. Xie, Sci. Total Environ., 2012, 424, 1-10.

23 M. Kaur, H. Zhang, L. Martin, T. Todd and Y. Qiang, Environ. Sci. Technol., 2013, 47, 11942-11959.

24 S. M. Husnain, W. Um, Y.-Y. Chang and Y.-S. Chang, Chem. Eng. J., 2017, 308, 798-808.

25 S. Banerjee, S. Roy, J. Chen and D. Chakravorty, J. Magn. Magn. Mater., 2000, 219, 45-52.

26 U. Wiedwald, L. Han, J. Biskupek, U. Kaiser and P. Ziemann, Beilstein J. Nanotechnol., 2010, 1, 24-47.

27 K. S. Martirosyan, C. Dannangoda, E. Galstyan and D. Litvinov, J. Appl. Phys., 2012, 111, 094311.

28 M. Bellusci, C. Aliotta, D. Fiorani, A. La Barbera, F. Padella, D. Peddis, M. Pilloni and D. Secci, J. Nanopart. Res., 2012, 14, 1-11.

29 G. Saito, Y. Nakasugi, T. Yamashita and T. Akiyama, Nanotechnology, 2014, 25, 135603.

30 S. Chaitoglou, M. R. Sanaee, N. Aguiló-Aguayo and E. Bertran, J. Nanomater., 2014, 2014, 9.

31 G. Salazar-Alvarez, M. Muhammed and A. A. Zagorodni, Chem. Eng. Sci., 2006, 61, 4625-4633.

32 H. Zhang and G. Zhu, Appl. Surf. Sci., 2012, 258, 4952-4959.

33 D. Soundararajan and K. H. Kim, Journal of Magnetics, 2014, 19, 5-9.

34 R. Yi, G. Ye, F. Wu, M. Wen, X. Feng and J. Chen, RSC Adv., 2014, 4, 37600-37608.

35 S. Hasany, I. Ahmed, J. Rajan and A. Rehman, Nanosci. Nanotechnol., 2012, 2, 148-158. 
36 Z. Mosleh, P. Kameli, M. Ranjbar and H. Salamati, Ceram. Int., 2014, 40, 7279-7284.

37 C. Okoli, M. Boutonnet, L. Mariey, S. Järås and G. Rajarao, J. Chem. Technol. Biotechnol., 2011, 86, 1386-1393.

38 Y. P. Yew, K. Shameli, M. Miyake, N. Kuwano, N. B. B. A. Khairudin, S. E. B. Mohamad and K. X. Lee, Nanoscale Res. Lett., 2016, 11, 1-7.

39 I. Šafařík and M. Šafaříková, in nanostructured materials, Springer, 2002, pp. 1-23.

40 S. M. Husnain, J.-H. Kim, C.-S. Lee, Y.-Y. Chang, W. Um and Y.-S. Chang, RSC Adv., 2016, 6, 35825-35832.

41 O. Philippova, A. Barabanova, V. Molchanov and A. Khokhlov, Eur. Polym. J., 2011, 47, 542-559.

42 R. S. Carvalho, A. L. Daniel-da-Silva and T. Trindade, Particle \& Particle Systems Characterization, 2016.

43 Y. Zhao, J. Li, L. Zhao, S. Zhang, Y. Huang, X. Wu and X. Wang, Chem. Eng. J., 2014, 235, 275-283.

44 X. Chen, L. He, R. Liu, C. Zhang, B. Liu and Y. Tang, RSC Adv., 2015, 5, 56658-56665.

45 Y. Liu and M. Guo, Molecules, 2015, 20, 8583-8594.

46 S. Sadeghi, H. Azhdari, H. Arabi and A. Z. Moghaddam, J. Hazard. Mater., 2012, 215, 208-216.

47 D. Li, S. Egodawatte, D. I. Kaplan, S. C. Larsen, S. M. Serkiz and J. C. Seaman, J. Hazard. Mater., 2016, 317, 494-502.

48 M. Zeng, Y. Huang, S. Zhang, S. Qin, J. Li and J. Xu, RSC Adv., 2014, 4, 5021-5029.

49 F. N. Smith, W. Um, C. D. Taylor, D.-S. Kim, M. J. Schweiger and A. A. Kruger, Environ. Sci. Technol., 2016, 50, 5216-5224.

50 M.-S. Lee, W. Um, G. Wang, A. A. Kruger, W. W. Lukens, R. Rousseau and V.-A. Glezakou, Nat. Commun., 2016, 7, 12067.

51 X. Liu, G.-R. Chen, D.-J. Lee, T. Kawamoto, H. Tanaka, M.-L. Chen and Y.-K. Luo, Bioresour. Technol., 2014, 160, 142-149.

52 T. Sasaki and S. Tanaka, Chem. Lett., 2011, 41, 32-34.

53 C. Thammawong, P. Opaprakasit, P. Tangboriboonrat and P. Sreearunothai, J. Nanopart. Res., 2013, 15, 1689.

54 H.-M. Yang, S.-C. Jang, S. B. Hong, K.-W. Lee, C. Roh, Y. S. Huh and B.-K. Seo, J. Alloys Compd., 2016, 657, 387393.

55 J. Jang and D. S. Lee, Ind. Eng. Chem. Res., 2016, 55, 38523860.

56 M. Zhu and G. Diao, Nanoscale, 2011, 3, 2748-2767.

57 S. Xu, Y. Zhao, F. Zheng and Y. Zhang, J. Mater. Sci., 2016, 51, 2550-2557.

58 Q. Liu, W. Li, W. Zhao, L. Tan, X. Jing, J. Liu, D. Song, H. Zhang, R. Li and L. Liu, RSC Adv., 2016, 6, 22179-22186.

59 R. M. Cornell and U. Schwertmann, The iron oxides: structure, properties, reactions, occurrences and uses, John Wiley \& Sons, 2003.

60 M. H. Sousa, F. A. Tourinho, J. Depeyrot, G. J. da Silva and M. C. F. Lara, J. Phys. Chem. B, 2001, 105, 1168-1175.

61 M. N. R. Kumar, React. Funct. Polym., 2000, 46, 1-27.

62 J.-s. Wang, R.-t. Peng, J.-h. Yang, Y.-c. Liu and X.-j. Hu, Carbohydr. Polym., 2011, 84, 1169-1175.
63 A. A. Galhoum, M. G. Mahfouz, A. A. Atia, S. T. AbdelRehem, N. A. Gomaa, T. Vincent and E. Guibal, Ind. Eng. Chem. Res., 2015, 54, 12374-12385.

64 D. Hritcu, D. Humelnicu, G. Dodi and M. I. Popa, Carbohydr. Polym., 2012, 87, 1185-1191.

65 L. Zhou, C. Shang, Z. Liu, G. Huang and A. A. Adesina, J. Colloid Interface Sci., 2012, 366, 165-172.

66 A. Tripathi, J. S. Melo and S. F. D'Souza, J. Hazard. Mater., 2013, 246, 87-95.

67 D. Yuan, L. Chen, X. Xiong, L. Yuan, S. Liao and Y. Wang, Chem. Eng. J., 2016, 285, 358-367.

68 L. Chen and B. Li, Anal. Methods, 2012, 4, 2613-2621.

69 N. T. Tavengwa, E. Cukrowska and L. Chimuka, J. Hazard. Mater., 2014, 267, 221-228.

70 W. Song, M. Liu, R. Hu, X. Tan and J. Li, Chem. Eng. J., 2014, 246, 268-276.

71 M. O. Abd El-Magied, J. Eng., 2016, 2016, 7214348.

72 X. Zhang, J. Wang, R. Li, Q. Dai and L. Liu, New J. Chem., 2013, 37, 3914-3919.

73 L. Tan, J. Wang, Q. Liu, Y. Sun, H. Zhang, Y. Wang, X. Jing, J. Liu and D. Song, Colloids Surf., A, 2015, 466, 85-91.

74 Z. Guo, Y. Li, S. Pan and J. Xu, J. Mol. Liq., 2015, 206, 272277.

75 C. Ding, W. Cheng, Y. Sun and X. Wang, J. Hazard. Mater., 2015, 295, 127-137.

76 A. Ghaemi, M. Maghsudi, F. Hanifpour and M. Samadfam, Int. J. Chemoinf. Chem. Eng. (IJCCE), 2013, 3, 8-18.

77 S. Yang, P. Zong, X. Ren, Q. Wang and X. Wang, ACS Appl. Mater. Interfaces, 2012, 4, 6891-6900.

78 S. Yu, X. Wang, X. Tan and X. Wang, Inorg. Chem. Front., 2015, 2, 593-612.

79 P. Zong, S. Wang, Y. Zhao, H. Wang, H. Pan and C. He, Chem. Eng. J., 2013, 220, 45-52.

80 H. Yang, L. Sun, J. Zhai, H. Li, Y. Zhao and H. Yu, J. Mater. Chem. A, 2014, 2, 326-332.

81 Y. Zhao, J. Li, S. Zhang, H. Chen and D. Shao, RSC Adv., 2013, 3, 18952-18959.

82 L. Shao, X. Wang, Y. Ren, S. Wang, J. Zhong, M. Chu, H. Tang, L. Luo and D. Xie, Chem. Eng. J., 2016, 286, 311319.

83 K. G. Bhattacharyya and S. S. Gupta, Adv. Colloid Interface Sci., 2008, 140, 114-131.

84 L. C. Oliveira, R. V. Rios, J. D. Fabris, K. Sapag, V. K. Garg and R. M. Lago, Appl. Clay Sci., 2003, 22, 169-177.

85 S. Yang, P. Zong, J. Hu, G. Sheng, Q. Wang and X. Wang, Chem. Eng. J., 2013, 214, 376-385.

86 Z. Lu, Z. Hao, J. Wang and L. Chen, J. Ind. Eng. Chem., 2016, 34, 374-381.

87 M. Darder, Y. González-Alfaro, P. Aranda and E. RuizHitzky, RSC Adv., 2014, 4, 35415-35421.

88 X. Zhang, L. Ji, J. Wang, R. Li, Q. Liu, M. Zhang and L. Liu, Colloids Surf., A, 2012, 414, 220-227.

89 S. Yang, N. Okada and M. Nagatsu, J. Hazard. Mater., 2016, 301, 8-16.

90 M. Kaminski, L. Nunez, M. Pourfarzaneh and C. Negri, Sep. Purif. Technol., 2000, 21, 1-8. 
91 Y. Namiki, T. Ueyama, T. Yoshida, R. Watanabe, S. Koido and T. Namiki, Sci. Rep., 2014, 4, 6294.

92 F.-L. Fan, Z. Qin, J. Bai, W.-D. Rong, F.-Y. Fan, W. Tian, X.-L. Wu, Y. Wang and L. Zhao, J. Environ. Radioact., 2012, 106, 40-46.

93 W. Guo, C. Nie, L. Wang, Z. Li, L. Zhu, L. Zhu, Z. Zhu, W. Shi and L. Yuan, Sci. China: Chem., 2016, 59, 629-636.

94 G. H. Mirzabe and A. R. Keshtkar, J. Radioanal. Nucl. Chem., 2015, 303, 561-576.

95 A. Rezaei, H. Khani, M. Masteri-Farahani and M. K. Rofouei, Anal. Methods, 2012, 4, 4107-4114.

96 L. Tan, X. Zhang, Q. Liu, J. Wang, Y. Sun, X. Jing, J. Liu, D. Song and L. Liu, Dalton Trans., 2015, 44, 6909-6917.

97 S. Sayin and M. Yilmaz, Desalination, 2011, 276, 328-335.

98 R. Yi, G. Ye, F. Wu, D. Lv and J. Chen, J. Radioanal. Nucl. Chem., 2016, 308, 599-608.

99 L. Zhou, H. Zou, Y. Wang, Z. Liu, Z. Huang, T. Luo and A. A. Adesina, J. Radioanal. Nucl. Chem., 2016, 1-9.

100 L. Tan, X. Zhang, Q. Liu, X. Jing, J. Liu, D. Song, S. Hu, L. Liu and J. Wang, Colloids Surf., A, 2015, 469, 279-286.

101 R. R. Sheha, J. Colloid Interface Sci., 2012, 388, 21-30.

102 T. Sasaki and S. Tanaka, Chem. Lett., 2012, 41, 32-34.

103 C. Thammawong, P. Opaprakasit, P. Tangboriboonrat and P. Sreearunothai, J. Nanopart. Res., 2013, 15, 1-10.

104 L. Chang, S. Chang, W. Chen, W. Han, Z. Li, Z. Zhang, Y. Dai and D. Chen, RSC Adv., 2016, 6, 96223-96228.

105 L. C. B. Stopa and M. Yamaura, Int. J. Nucl. Energy Sci. Technol., 2010, 5, 283-289.

106 M. G. Mahfouz, A. A. Galhoum, N. A. Gomaa, S. S. AbdelRehem, A. A. Atia, T. Vincent and E. Guibal, Chem. Eng. J., 2015, 262, 198-209.

107 K. Z. Elwakeel and A. A. Atia, J. Cleaner Prod., 2014, 70, $292-$ 302.

108 L. Zhou, H. Zou, Y. Wang, Z. Huang, Y. Wang, T. Luo, Z. Liu and A. A. Adesina, J. Radioanal. Nucl. Chem., 2016, 308, 935946.

109 J. Xu, L. Zhou, Y. Jia, Z. Liu and A. A. Adesina, J. Radioanal. Nucl. Chem., 2015, 303, 347-356.

110 Z. Cheng, Z. Gao, W. Ma, Q. Sun, B. Wang and X. Wang, Chem. Eng. J., 2012, 209, 451-457.

111 Y. Chen and J. Wang, Nucl. Eng. Des., 2012, 242, 445-451.

112 Y. Zhu, J. Hu and J. Wang, Prog. Nucl. Energy, 2014, 71, 172178.

113 S.-l. Yu, Y. Dai, X.-h. Cao, Z.-b. Zhang, Y.-h. Liu, H.-j. Ma, S.-j. Xiao, Z.-j. Lai, H.-j. Chen and Z.-y. Zheng, J. Radioanal. Nucl. Chem., 2016, 310, 651-660.

114 J. Li, Z. Guo, S. Zhang and X. Wang, Chem. Eng. J., 2011, 172, 892-897.

115 D. Yuan, L. Chen, X. Xiong, Q. Zhang, S. Liao, L. Yuan and Y. Wang, J. Radioanal. Nucl. Chem., 2016, 309, 1227-1240.

116 A. M. Atta and Z. F. Akl, Mater. Chem. Phys., 2015, 163, 253261.
117 Z. F. Akl, S. M. El-Saeed and A. M. Atta, J. Ind. Eng. Chem., 2016, 34, 105-116.

118 S.-C. Jang, G. Kim, S. Hong, H.-M. Yang, K.-W. Lee, J.-K. Moon, B.-K. Seo, Y. Cho, Y. Huh and C. Roh, Int. J. Environ. Sci. Technol., 2015, 12, 3695-3700.

119 G. Peng, D. Ding, F. Xiao, X. Wang, N. Hun, Y. Wang, Y. Dai and Z. Cao, J. Radioanal. Nucl. Chem., 2014, 301, 781-788.

120 X. Zhang, C. Jiao, J. Wang, Q. Liu, R. Li, P. Yang and M. Zhang, Chem. Eng. J., 2012, 198, 412-419.

121 L. Li, M. Xu, M. Chubik, M. Chubik, A. Gromov, G. Wei and W. Han, RSC Adv., 2015, 5, 41611-41616.

122 L. Wang, Z. Yang, J. Gao, K. Xu, H. Gu, B. Zhang, X. Zhang and B. Xu, J. Am. Chem. Soc., 2006, 128, 13358-13359.

123 Y. Zhao, J. Li, S. Zhang, H. Chen and D. Shao, RSC Adv., 2013, 3, 18952-18959.

124 L. Tan, J. Wang, Q. Liu, Y. Sun, X. Jing, L. Liu, J. Liu and D. Song, New J. Chem., 2015, 39, 868-876.

125 L. Chen, D. Zhao, S. Chen, X. Wang and C. Chen, J. Colloid Interface Sci., 2016, 472, 99-107.

126 D. Zhao, L. Chen, M. Sun and F. Li, J. Radioanal. Nucl. Chem., 2015, 306, 221-229.

127 X. Wang and J. Yu, J. Radioanal. Nucl. Chem., 2015, 303, 807-813.

128 Y. Li, G. Sheng and J. Sheng, J. Mol. Liq., 2014, 199, 474-480.

129 D. Li, B. Zhang and F. Xuan, J. Mol. Liq., 2015, 211, 203-209.

130 H. Chen, J. Li, S. Zhang, X. Ren, Y. Sun, T. Wen and X. Wang, Radiochim. Acta, 2013, 101, 785-794.

131 D. Li, B. Zhang and F. Xuan, J. Mol. Liq., 2015, 209, 508-514.

132 H. Yang, H. Li, J. Zhai, L. Sun, Y. Zhao and H. Yu, Chem. Eng. J., 2014, 246, 10-19.

133 X. Zhang, J. Wang, R. Li, Q. Dai, R. Gao, Q. Liu and M. Zhang, Ind. Eng. Chem. Res., 2013, 52, 10152-10159.

134 P. Liu, W. Qi, Y. Du, Z. Li, J. Wang, J. Bi and W. Wu, Sci. China: Chem., 2014, 57, 1483-1490.

135 Y. Lu, J. Yu and S. Cheng, J. Radioanal. Nucl. Chem., 2015, 303, 2371-2377.

136 T. A. Saleh, M. Tuzen and A. Sarı, Chemical Engineering Research and Design, 2016.

137 W. He, Y. Chen, W. Zhang, C. Hu, J. Wang and P. Wang, Korean J. Chem. Eng., 2016, 33, 170-177.

138 H. Faghihian, M. Moayed, A. Firooz and M. Iravani, C. R. Chim., 2014, 17, 108-117.

139 H. Faghihian, M. Moayed, A. Firooz and M. Iravani, J. Colloid Interface Sci., 2013, 393, 445-451.

140 W. Wang, Q. Feng, K. Liu, G. Zhang, J. Liu and Y. Huang, Solid State Sci., 2015, 39, 52-58.

141 S. Li, H. Bai, J. Wang, X. Jing, Q. Liu, M. Zhang, R. Chen, L. Liu and C. Jiao, Chem. Eng. J., 2012, 193, 372-380.

142 X. Zheng, J. Dou, J. Yuan, W. Qin, X. Hong and A. Ding, J. Environ. Sci., 2017, 56, 12-24.

143 A. Drenkova-Tuhtan, M. Schneider, M. Franzreb, C. Meyer, C. Gellermann, G. Sextl, K. Mandel and H. Steinmetz, Water Res., 2017, 109, 77-87. 